\title{
Uncovering Genomic Regions Regulating the Superoxide Dismutase, Flavonoids, Anthocyanins, Carotenoids, y-Oryzanol and Antioxidant Activity in Rice Through Association Mapping
}

\author{
E Pandit \\ ICAR-National Rice Research Institute \\ P Sanghamitra \\ ICAR-National Rice Research Institute \\ SR Barik \\ ICAR-National Rice Research Institute \\ R Bastia \\ ICAR-National Rice Research Institute \\ SP Mohanty \\ ICAR-National Rice Research Institute \\ A Behera \\ ICAR-National Rice Research Institute \\ A Moharana \\ ICAR-National Rice Research Institute \\ N Basak \\ ICAR-National Rice Research Institute \\ SK Pradhan ( $\sim$ pradhancri@@gmail.com ) \\ ICAR-National Rice Research Institute
}

\section{Research Article}

Keywords: ABTS, antioxidant capacity, anthocyanins, association mapping, carotenoids, flavonoids, y-oryzanol, superoxide dismutase

Posted Date: June 1st, 2021

DOI: https://doi.org/10.21203/rs.3.rs-558142/v1

License: () (1) This work is licensed under a Creative Commons Attribution 4.0 International License. Read Full License 


\section{Abstract}

Consumption of antioxidants rich rice has impressive health benefits. Five antioxidant traits viz., superoxide dismutase, flavonoids, anthocyanins, $\gamma$-oryzanol and ABTS were mapped in a panel population using 136 SSR markers through association mapping. A panel population containing 120 germplasm lines by including genotypes from all the phenotypic groups of the six antioxidant traits from the original shortlisted 270 rice genotypes. Donor lines rich in multiple antioxidant compounds were identified from the population. The population was classified into 4 genetic groups and showed fair degree of correspondence with the antioxidants content. A total of 14 significant marker-trait associations for antioxidants were detected of which 3 QTLs namely $q A N C 3$, qPAC12-2 for anthocyanin content and $q A C 12$ for ABTS activity were validated in the population. Eleven putative QTLs such as $q T A C 1.1$ and $q T A C 5.1$ for anthocyanin content; qSOD1.1, qSOD5.1 and qSOD10.1 for SOD; qTFC6.1, qTFC11.1 and qTFC12.1 for TFC; qOZ8.1 and qOZ11.1 for -oryzanol and qAC11.1 for ABTS were detected to be novel loci. Co-localization of the QTLs detected for OZ11.1, TFC11.1 and AC11.1 regulating Y-oryzanol, flavonoid and anthocyanin content, respectively while PAC12.2 for anthocyanin content remained closer to TFC12.1 for flavonoid content. These QTLs will be useful in the antioxidant improvement programs in rice.

\section{Background}

Nutritional health of a country has significant effect on economic performance of that country ${ }^{1}$ (Alsan etal., 2006). About half of the global population is dependent on rice for their primary diet, but majority of them are affected by malnutrition, Fe and $\mathrm{Zn}$ deficiency, and oxidative stress-related health problems such as stroke, psoriasis, type II diabetes, heart diseases, obesity, cancers, dermatitis, and rheumatoid arthritis ${ }^{2,3}$. Thus, enrichment of staple foods with Fe, Zn, and antioxidant compounds have been prioritized through biofortification ${ }^{4,5,6,7,8}$. Since rice is the primary source of nutrition to meet daily calorie and protein intake of more than two billion people around the world ${ }^{9}$ improving nutraceutical value of rice grain enriching with antioxidant compounds could be the best option to onslaught the stress related disorders and to utilize rice as health promoting food to improve human health. Also in recent years, consumption of whole grain pigmented rice enriched with antioxidant compounds is gaining popularity in developed and developing countries as it is advised to improve the health by reducing the risk of such chronic diseases ${ }^{10,11}$. Thus, rice breeding programs need to focus on the development of nutrient dense rice for which improvement of the antioxidant traits is a necessity to meet the nutritional quality standards.

Antioxidants are present in plants both in enzymatic and non-enzymatic forms: enzymatic antioxidants are catalases, peroxidases, superoxide dismutases, glutathione and other proteins and non-enzymatic antioxidant includes phenolic defense compounds (vitamin E, flavonoids, phenolic acids and other phenols); nitrogen compounds (alkaloids, amino acids and amines), carotenoids and chlorophyll derivatives ${ }^{12,13}$. The enzymatic antioxidants protect the plant cell from damage caused by reactive oxygen species and acts as defense system for maintaining the structural and functional integrity of a cell by inhibiting the oxidative deterioration to macromolecules like lipid, protein and nucleic acid ${ }^{13,14,15}$. Hence, improvement of these traits will lead to development of superior quality seed. Non-enzymatic antioxidants such as phenolic acids, flavonoids, anthocyanins and proanthocyanidins, tocopherols and tocotrienols (vitamin E) and $y$-oryzanol reported to be higher in pigmented rice (rice with red, black and purple pericarp). The antioxidants show impressive health benefits like reducing oxidative stress and cholesterol levels in human body, lowering the chances of type-2 diabetes, obesity, cancer etc. ${ }^{16,17,18}$. These antioxidant traits are complex traits, polygenic in nature and quantitatively inherited ${ }^{19}$. Understanding the genetic bases of these complex antioxidant traits and identification of major QTLs are essential for marker-assisted breeding for improvement of these phytochemicals to ameliorate the increasing nutrition problems of the rice-eating population and seed quality as well.

Increasing carotenoid content in rice grains remained an important breeding objective over the past decades due to its antioxidative, anti-inflammatory properties and most importantly as dietary source of provitamin $\mathrm{A}^{20}$. Identification of QTLs/gene for higher carotenoid content and development of functional markers is slow in rice as carotenoids are not detected in rice endosperm ${ }^{20}$. However, there exist a huge potential in the exploitation of genetic variability of the carotenoid content in red and black rice that accumulate high carotenoid content, while white rice accumulates very little 21,22 . Color of the pigmented rice has several health promoting effect due to two primary pigments, anthocyanidin and proanthocyanidin that are present in the pericarp and aleurone layer of rice grain. The proanthocyanidin content in rice which impart red colour to rice pericarp was considered to be controlled by interaction of $R c$ and $R d$ genes ${ }^{23,24,25}$. Whereas anthocyanidins that impart purple-black pericarp to rice grain is controlled by two loci, $P b$ and $P p^{26}$. The Pb gene responsible for purple colour has been fine mapped and it was suggested that the Ra gene present in the $25 \mathrm{~kb}$ of delimited region of the $P b$ locus may be the $P b$ gene, and the purple pericarp characteristic of rice is caused by a two bases deletion (GT) within exon 7 of the $R a^{27,28,29}$. Two genes, dihydro flavonol reductase (DFR), and anthocyanin synthase $(A N S)$ located on chromosome 1 controlled the anthocyanin content ${ }^{30}$. However, a recent study reported that A1 (Kala1/Rd/OsDFR), C1(OsC1) determine purple colour of the grain and pattern of anthocyanin pigmentation is determined by the allelic status of $A 1, C 1$, and $S 1$ (OsANS1) ${ }^{31}$. Kala $4 / \mathrm{OsB} 2 / \mathrm{Pb}$ gene was mainly responsible for black pigmentation in rice pericarp $32,33,34,35,36$. Although several genes responsible for pericarp pigmentation have already been identified but possibility of additional genes and variants associated with these traits exist and need to be discovered.

The genetic analyses for identification and fine mapping of genes and QTLs for pericarp pigmentation in rice have been published by using various mapping populations ${ }^{10,25,35,37,39,40}$. However, few reports on QTL mapping are available on gamma-oryzanol, total phenolics content (TPC), total flavonoids content (TFC), ABTS (Azinobis 3-ethyl benzothiazoline-6-sulfonic acid) and SOD (Super oxide dismutase) activity in rice. Flavonoids are the major class of phenolic compounds responsible for color in rice. Rice bran contains seven flavonoids of which Tricin is the key compound. Antioxidants protect the cells against free radicals, which may cause diseases in human. The QTLs, $q P H-12, q F L-2-1$ and $q A C-1$ The genetic control of phenolic content, flavonoid content, andantioxidant capacity in rice have reported by various workers ${ }^{10,37,38,40,41}$. Mapping report of $Y$-oryzanol content in rice identified eight $Q T L s$ from a single publication ${ }^{42}$. A recent report indicated the possibility of marker-trait association for phenolics, carotenoids, anthocyanin, $\gamma$-oryzanol and other antioxidant contents in rice ${ }^{43}$. 
Enhancement of anthocyanin content has been attempted through genetic engineering of anthocyanin biosynthesis transgenes that has generated 'Purple Endosperm Rice'44. Attempts have been made to develop few pigmented rice varieties like'Rubi' and 'Onix' of Brazil ${ }^{45}$ and 'Rice berry" of Thailand ${ }^{46}$. Also, some advanced breeding lines are available $33,36,47,48,49$. Though several studies reported about genes for these antioxidant traits of which some genes have been fine mapped in certain cases $(R c, R d, P b)$ and each adopted a different gene coding system which is still confusing for which more firm genes/loci should be identified to explain these complex traits ${ }^{19}$. There by development of trait-specific markers will accelerate the efforts to breed high yielding pigmented rice varieties.

The genetic diversity and structure of the population will be helpful for detecting marker-trait association which could be useful for trait enhancement in molecular breeding programs. In order to avoid spurious association of marker-phenotype in a population, population structure (Q) with relative kinship (K) analyses is essential to check the correctness of the panel population composition for linkage disequilibrium (LD) mapping analyses ${ }^{50,51,52}$. Thus, association estimate based on both the models of Generalized linear model (GLM) and Mixed linear model (MLM) is considered appropriate for mapping complex traits that have shown to perform better than other model analyses.

Association mapping based on linkage disequilibrium has emerged as a powerful alternative strategy for identifying genes or quantitative trait loci (QTL) for various complex traits in plants in a natural variable population by examining the marker-trait associations. In the present study, we have identified the marker loci/QTLs underlying the naturally occurring variations of antioxidant traits and antioxidant activity by association mapping. We have used a panel population of 120 genotypes (67 white and 53 red grain) shortlisted from 270 diverse genotypes (121 white and 149 red grain) of India through phenotyping of six physio-biochemical traits (carotenoids, SOD, total anthocyanins, $y$-oryzanols, TFC, and ABTS). Rice microsatellite markers were used to study the population genetic structure, diversity and association of molecular markers with these phytochemical traits to improve nutritional quality of rice.

\section{Materials And Methods}

\section{Seed material}

The study material includes 270 genotypes (landraces and cultivars) of 121 white and 149 colored rice grains. The initial population was shortlisted on the basis of maturity duration (upto 135 days) and kernel color (red, black, purple and white) from about 1000 germplasm lines. Seeds of these germplasm were collected from Gene bank, ICAR-NRRI, Cuttack and were grown in the experimental plot of the Institute during wet season, 2018. The genotypes were grown in randomized complete block design in three rows each following spacing of $20 \times 15 \mathrm{~cm}$ in two replications following recommended package and practices. Each replication is divided into 5 blocks accommodating 54 germplasm lines in each block. Panicles of middle row plants of each replication were harvested, sun dried for 4-5 days to reduce the moisture content to 11-12\%, stored for three months to remove dormancy and then used for estimation of superoxide dismutase, flavonoids, anthocyanins, carotenoids, $y$-oryzanol and antioxidant activity. A representative panel population containing 120 germplasm lines was prepared from the original 270 germplasm lines (120 genotypes consisting of 67 white and 53 red grain rice). The panel population was raised during wet seasons, 2019 and 2020 and the antioxidants were estimated. The panel population (120) is used for genotyping for association mapping of antioxidant traits (Table 1). The plant experiments were performed in accordance with relevant guidelines and regulations.

\section{Phenotyping for antioxidant traits}

The seed samples were dehulled by the Satake rice huller, Japan and were ground into flour by a grinding machine (Glenmini grinder) and sieved through 100 mesh size and then stored at $4^{0} \mathrm{C}$ for the experiment. Analysis of all the traits were based on dry matter basis except for carotenoid content which were estimated based on fresh weight basis. Leaf samples from 10 days old seedling grown on petriplate at $30^{0} \mathrm{C}$ were used for estimation of carotenoids ( $\mathrm{mg} \mathrm{g}{ }^{-1}$ )

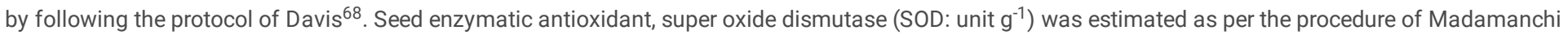
et al. ${ }^{69}$. Non-enzymatic antioxidant, total anthocyanin content (TAC: $\mathrm{mg}_{100 \mathrm{~g}^{-1} \text { ) was estimated by the procedure of Fuleki and Francis }}{ }^{70}$. Estimation of $\mathrm{Y}^{-}$ Oryzanol (GO:mg $100 \mathrm{~g} \mathrm{~g}^{-1}$ ) was done according to Bucci et al. ${ }^{71}$ with minor modifications. Total flavonoids content (TFC) was estimated as per the procedure of Eberhardt et al. ${ }^{72}$ and expressed as catechine equivalent (mg CEt $100 \mathrm{~g} \mathrm{~g}^{-1}$ ). Antioxidant activity, ABTS (2,2'-azino-bis (3-ethylbenzothiazoline-6-sulfonic acid) radical scavenging was assayed by modified protocol of Serpen et al. ${ }^{73}$ and expressed as $\%$ inhibition.

\section{Statistical analysis}

Cropstat software7.0. was used for analysis of variance (ANOVA) for each trait including the estimation of mean, range, and coefficient of variation (CV \%). Pearson's correlation coefficients were analyzed to find out the relationship among the various antioxidant traits, based on the mean values of the 120 genotypes and presented in correlation matrix heatmap by using PAST software. The germplasm lines were classified into six groups as very high, high, medium, low and very low category based on mean values antioxidant traits.

\section{Genomic DNA isolation, PCR analysis and selection of SSR markers}

The genomic DNA was isolated from 15 days-old seedlings of the germplasm lines by adopting CTAB method ${ }^{74}$ (Murray and Thompson 1980 ). The 136 SSR (simple sequence repeat) markers were taken from the database (http://gramene.org/) available in the public domain (Supplementary Table 5). The DNA fragments were resolved in gel electrophoresis for quantification of isolated DNA. PCR analysis was done using the markers selected based on positions covering all the chromosomes to illustrate the diversity and to identify the polymorphic loci among the 120 rice germplasm lines (Table 1). Conditions of reaction was set to initial denaturation step $\left(2 \mathrm{~min}, 95^{\circ} \mathrm{C}\right)$, followed by 35 cycles of denaturation $\left(30 \mathrm{~s}, 95^{\circ} \mathrm{C}\right)$ and annealing/extension $\left(30 \mathrm{~min}, 55^{\circ} \mathrm{C}\right)$, extension $\left(2 \mathrm{~min}, 72^{\circ} \mathrm{C}\right)$, final extension $\left(5 \mathrm{~min}, 72^{\circ} \mathrm{C}\right.$ ) and store at $4^{\circ} \mathrm{C}$ (infinity). The PCR products were electrophoresed using $3 \%$ agarose gel containing 
$0.80 \mathrm{~g} \mathrm{ml}^{-1}$ ethidium bromide and. $50 \mathrm{bp}$ DNA ladder was used to determine the size of amplicons. The gel was run for $4 \mathrm{~h}$ at $2.5 \mathrm{~V} \mathrm{~cm}{ }^{-1}$ and photographed using a Gel Documentation System (SynGene). Earlier publications of ${ }^{75,76,77}$ were followed for DNA isolation, electrophoresis and imaging techniques.

\section{Molecular data analysis}

Presence or absence of amplified products obtained on the basis genotype-primer combination was used to score the data. A binary data matrix was used as discrete variables for the entry of our result data. The parameters namely polymorphic information content (PIC), observed heterozygosity (H), number of alleles (N), major allele frequency (A) and gene diversity (GD) for each SSR locus ${ }^{78}$ was analysed by using, 'Power Marker Ver3.25' software. A Bayesian model based clustering approach STRUCTURE 2.3.6 software was used to analysis genetic data and obtain population structure ${ }^{79}$. STRUCTURE software was run with $\mathrm{K}$ varying from 1 to 10 , with 10 iterations for each $\mathrm{K}$ value to derive the ideal number of groups. A high throughput parameter set of burn-in period of the 150,000 followed by 150,000 Markov Chain Monte Carlo (MCMC) replications was adapted during the running period. Highest value of $\Delta K$ was pick up from Evanno table used to detect the subpopulation groups from the panel of populations in the next step. The maximal value of $L(K)$ was identified using the exact number of sub-populations. The model choice criterion to detect the most probable value of $\mathrm{K}$ was $\Delta \mathrm{K}$, an ad-hoc quantity related to the second-order change of the log probability of data with respect to the number of clusters inferred by STRUCTURE ${ }^{80}$. For estimation of the $\Delta K$-value as function of $K$ showing a clear peak as the optimal K-value Structure Harvester was used. The principal coordinate analysis of all the genotypes and unweighted neighbor joining unrooted tree for NEI coefficient dissimilarity index ${ }^{82}$ with bootstrap value of 1,000 were obtained by using DARwin 5 software ${ }^{83}$. Analysis of molecular variance (AMOVA) using GenAIEx 6.5 software was used to estimate the presence of molecular variance across the whole population, within a population and between the sub-population structures (FIT, FIS, FST) calculated by the deviation from Hardy-Weinberg expectation. The procedures followed in earlier publications were adopted for molecular data analysis ${ }^{51,67,84}$.

To analyze the marker-trait association for mapping study of the seed antioxidant traits in rice, the software "TASSEL 5.0" was used. General linear model and Mixed linear model in TASSEL 5.0 were used to perform the genetic association between the phenotypic traits and molecular markers ${ }^{85}$. By considering the significant $\mathrm{p}$-value and $\mathrm{r}^{2}$ value convincing associated markers were identified. The associations of markers were further confirmed by the Q-Q plot generated by the software. Linkage disequilibrium plot was obtained using LD measured $\mathrm{r}^{2}$, between pair of markers is plotted against the distance between the pair. Also, the accuracy of the marker-trait association by estimating the FDR adjusted p-values (q-values) using R software as described in the earlier publications $\mathbf{6}^{6,61,67}$.

\section{Results}

\section{Phenotyping of the population for antioxidant content in rice}

A total of six antioxidant compounds including one antioxidant enzyme namely superoxide dismutase, flavonoids, anthocyanins, carotenoids, $y$-oryzanol and ABTS were estimated from 270 genotypes during wet seasons of 2019 (Supplementary Table 1). Wide variation exists among the germplasm lines for 6 antioxidant compounds. The germplasm lines were classified into 5 groups based on the phenotying results of each compounds (Fig. 1). The frequency distribution of germplasm lines showed various groups or populations for each compound and enzyme (Fig. 1). A panel population was preparedby selecting120 genotypes representing each group and trait from the original population of 270 germplasm lines (Table 1; Fig. 2). The mean estimates of 6 antioxidants obtained from the representative panel population showed wide variation among the genotypes for each trait (Table 1). Very high values of carotenoid content was found in grmplasm lines Ac. 44598, Ac. 44597, and Ac. 9005. Very high TAC content was estimated from Ac. 43670 , Ac. 43660 and Ac. 43675. Germplasm lines namely AC. 9063, AC. 20371 and AC-20627 showed very high level of y-oryzanol in the seed. Good donor lines having very high TFC content, namely Ac. 43670, Ac. 43660, Ac. 44646, Ac. 44592, Ac. 44595, Ac. 43737, Ac. 43738 and Ac. 43676 were identified. The SOD level was very high in the seeds of genotypes such as Ac. 20317, Palinadhan-1, Ac.20362, Ac. 20328, Gochi, Chatuimuchi, Ac. 20770, Ac. 20920, Ac. 20907, Magra and Chinamal. The potential donors identified from the population for showing very high level of ABTS were Ac. 44592, Ac. 43670, Ac.4460, Ac. 44595, Ac. 44588, Ac. 43660, Ac. 43738 and Ac. 43732, However, a higher level of antioxidants such as more than 3 compounds in Ac. 44592, Ac. 44646, Ac. 44595, Ac. 43660, Ac. 43738, Ac. 43660, and Ac.43669 were indentified from the germplasm lines.

\section{Relatedness among germplasm lines for antioxidant compounds through Genotype-by-trait biplot analysis}

The scatter diagram was plotted taking the first two principal components to generate genotype-by-trait biplot graph for the 6 antioxidants estimated from the 120 genotypes present in the panel (Fig. 3). The first and second principal components showed 68.3 and $19.8 \%$ of the total variability with eigen values of 8064 and 2342, respectively (Supplementary Fig. 1). y-oryzanol contributed maximum diversity among the 6 antioxidant compounds in the genotypes present in the panel followed by TFC and ABTS (Fig. 3). The scattering pattern of genotypes in the 4 quadrants indicated that genotypes containing high estimates of antioxidants are placed in the quadrant 1 (top right) and II (bottom right). Higher estimates of antioxidants with multiple compounds containing genotypes have been encircled in the figure (Fig. 3). The top right ( ${ }^{\text {st }}$ quadrant) and bottom right ( $2^{\text {nd }}$ quadrant) accommodated majority of the genotypes containing high estimates of antioxidant compounds. The $3^{\text {rd }}$ (bottom left) quadrant kept most of the germplasm lines with moderate in antioxidant compounds while the $4^{\text {th }}$ quadrant (top left) accommodated majority of poor in antioxidant compounds containing germplasm lines (Fig. 3).

\section{Nature of association among antioxidant traits}

The association among 6 antioxidant traits revealed a strong positive correlation ( $r \geq 0.7)$ of TAC with TFC and TFC with ABTS. Moderate positive correlation (r: 0.5-0.7) of TAC with ABTS and weak positive correlation $(r<0.5)$ was observed for carotenoid with GO (Fig. 4). These antioxidant traits positively or negatively correlated may be controlled by the closely linked genes or because they might be structurally related. Therefore, a variety that accumulates high concentrations of one antioxidant may contain higher quantity of other correlated antioxidants. 
The panel population containing 120 germplasm lines which exhibited wide variation for the antioxidants was genotyped using 136 SSR markers. The genetic diversity parameters estimated from the panel population are presented in the Table 2. Genotyping results showed a total of 508 markers alleles from the population exhibiting mean alleles of 3.74 per locus. The number of alleles per locus ranged from 2 to 7 per marker. The highest numbers of alleles were produced by the marker RM493 in the studied panel for antioxidants content in rice. The measure for the variation by a marker in the population was analysed by the of availability major allele frequency parameter. The average major allele frequency linked to the polymorphic markers was computed to be 0.561 which showed a range of 0.279 (RM8044) and 0.925 (RM6054) (Table 2). The informativeness of a genetic marker is estimated by the PIC value. It ranged from 0.137 (RM6045 and 6054) to 0.787 (RM493) with average value of 0.496 . The observed mean heterozygosity (Ho) in the population was 0.116 which varied from 0.00 to 0.958 (RM3735). Twenty marker loci showed 0.00 Ho value in the panel population. The gene diversity (He) which gives a measure of genetic diversity in the panel population ranged from 0.142 (RM6054) to 0.813 (RM493) with a mean value of 0.555.

\section{Population Genetic Structure Analysis}

The diverse population for antioxidants was genotyped for genetic structure and analyzed by adopting probable sub-populations (K) and selecting higher delta K-value by applying the STRUCTURE 2.3.6 software. The rate of change in the log probability of data between successive $\mathrm{K}$ values is the delta $\mathrm{K}$ value used in the analysis. The panel population was categorized into two sub-populations with a high $\Delta \mathrm{K}$ peak value of 264.2 at $\mathrm{K}=2$ among the assumed $\mathrm{K}$ (Supplementary Table 2; Supplementary Fig. 2). The two subpopulations were in the proportion of 0.277 and 0.723 for population 1 and population 2 , respectively. But, the subpopulations showed poor correspondence with antioxidants containing genotypes present in the studied population. Therefore, next $\Delta \mathrm{K}$ peak at $\mathrm{K}=3$ was compared in which the population was classified into 3 subpopulations. The 3 subpopulations showed genotypes in the proportion of $0.208,0.689$ and 0.103 in the inferred clusters for the sub-population 1, 2, and 3, respectively. The Fst1, Fst2 and Fst3 values were $0.3392,0.1664$ and 0.3701 for the sub-population 1, 2, and 3, respectively (Supplementary Table 2; Supplementary Fig. 3). The ancestry value of $\geq 80 \%$ obtained in a genotype grouped the genotype into the particular subpopulation.

The assumed subpopulations at K=3 differentiated the germplasm lines for antioxidant compounds but did not clearly separate for the SP2 and SP3 subpopulations. Hence, next $\Delta \mathrm{K}$ peak at $\mathrm{K}=4$ was considered for the subpopulations in which the population was classified into $4 \mathrm{genetic}$ groups. The antioxidant compounds present in the studied population showed a fair correspondence at $\mathrm{K}=4$ with inferred structure values in the subpopulations. Majority of the germplasm lines with high to very high antioxidants were present in the subpopulations 4 . The moderate value antioxidant containing germplasm lines are present in the subpopulation 2. Poor and moderate antioxidants containing germplasm lines were in subpopulation 1 while very poor to poor types are in the subpopulation 3 (Table 3; Fig. 5). The alpha value of the panel showed a low value $(\alpha=0.0578)$ estimated by the structure analysis at $K=4$. Positively skewed leptokurtic distributions were observed for the mean alpha-value while normally skewed leptokurtic distributions detected for all the 4 Fst values for the panel population showing a distinct variation in the distribution among the Fst values (Supplementary Fig. 4).

\section{Molecular variance (AMOVA) and LD decay plot analysis}

The closely related plants among themselves in a population are grouped into different subpopulations. The genetic variations obtained within and between the subpopulations at $\mathrm{K}=4$ were estimated by the analysis of molecular variance (AMOVA) (Table 4). The genetic variations estimated at $\mathrm{K}=4$ was computed to be $6 \%$ among the populations, nil among individuals and $94 \%$ variation within individuals of the panel population. Wright's $F$ statistics was used to know the deviation from Hardy-Weinberg's prediction. The parameter $F_{I S}$ was used to know the uniformity of individuals within the subpopulation and $F_{I T}$ for individual within the total population for differentiation of the population. The $F_{\mathrm{IT}}$ and $\mathrm{F}_{\mathrm{IS}}$ of the total population and within population estimated on the basis of 136 marker loci showed -0.148 and -0.235 , whereas the total population had $F_{\mathrm{ST}}$ value of 0.071 between the 4 subpopulations. Fst is used to know the subpopulations or population differentiation within the total population. A clear differentiation among the 4 subpopulations was observed from each other for their distribution pattern was based on the Fst values (Supplemental Fig. 4).

The association of alleles by different loci in a nonrandom manner is utilized in the marker-trait association analysis. Existence of marker-trait association is dependent on the LD decay rate in a population over a time period. The LD decay rate will indicate the possibility of new genes or allelic variants controlling the antioxidant compounds associated with molecular markers for these traits. Syntenic $r^{2}$ value was used to plot the linkage disequilibrium decay of the population versus the physical distance in million base pair (Fig. 6A). Tightly linked markers had higher $r^{2}$ value and the average $r^{2}$ values rapidly decreases for increase in linkage distance. In the LD plot it is observed that the LD decay in the beginning was delayed in the studied panel populations. However, a decline of LD decay was noticed in the curve for the associated markers at about 1-2 mega base pair and thereafter a gradual and very slow decay was noticed from the graph. The graph clearly indicated the continuance of linkage disequilibrium decay in the population for the studied antioxidant compounds in the rice population. The limitation for LD decay depends on non-random mating, mutation, selection, migration or admixture, and genetic drift will influence the estimates of LD. This LD decay plot also provided clue for creation of genetic admixture groups for various antioxidants compounds in the normal population. A similar trend was also noticed in the marker ' $\mathrm{P}$ ' versus marker ' $\mathrm{F}$ ' and marker $\mathrm{R}^{2}$ (Fig. $6 \mathrm{~B}$ ) curve. The detected markers from this study indicated the strength of the markers for the studied antioxidant compounds.

\section{Principal coordinates and cluster analyses for genetic relatedness among the germplasm lines}

The two dimensional plot for principal coordinate analysis (PCoA) was constructed based on the genotyping results of 136 SSR markers which classified the 120 germplasm lines as per the genetic relatedness among the lines (Fig. 7). The inertia showed by component 1 was $11.73 \%$ while $7.49 \%$ exhibited by the component 2. The germplasm lines were allotted different spots in the four quadrants forming 3 major groups (Fig. 7). The biggest group accommodated all the germplasm lines of the subpopulation 2 and 3 together and clustered in the $2^{\text {nd }}$ (bottom right) quadrant. The genotypes in the $1^{\text {st }}$ quadrant are divided into 
2 groups of which one group on the top of the $1^{\text {st }}$ quadrant forms the sp3 subpopulation with low to very low in antioxidant content in the seeds. The other group near to the axis 1 is all admix type of germplasm lines. Few germplasm lines of quadrant 2 and closer to the axis 1 are also admix genotypes. The admix genotypes present on both sides of axis 1 are depicted in black colour (Fig. 7).

The germplasm lines containing high to very high mean values of antioxidants are grouped together forming the subpopulation 4 . This subpopulation is present on the quadrant 3 (top left) and 4 (bottom left) and encircled in red color. The germplasm lines rich in antioxidants are placed both side of the axis 1 on the quadrant 3 and 4 (Fig. 7). The PCoA distributed all the germplasm lines into the four quadrants classifying into 4 clusters and a separate admixture group. The subpopulations clustered by PCoA showed correspondence with the population structure (Fig. 7). Germplasm lines namely Ac. 44594, Ac. 43669, Ac. 44597, Ac. 44588, Ac. 43737, Ac. 44595, Ac. 43676, Ac. 44597, Ac. 44592, Ac. 43738, and Ac. 44646 are placed together in one structure group present in the quadrant III \& IV and are rich in antioxidants. The PCoA placed germplasm lines in the Quadrant II which were mostly average in antioxidant content. This quadrant formed the group by placing all the germplasm lines of subpopulation 1 and 2 .

The Wards's clustering broadly grouped all the genotypes into two major groups. The largest cluster, cluster 1 accommodated 111 germplasm lines in which all poor to average containing antioxidants were present. The cluster II had 9 germplasm lines only. The dendrogram placed all the germplasm lines in this cluster II which were rich in antioxidant content. This cluster again subdivided into 2 sub groups which further divided into 6 sub-sub clusters. The cluster I was divided into two main sub clusters which finally divided into 32 small groups. All the clusters and small groups accommodated in the Ward's clustering approach were based on the antioxidant compounds content in the germplasm lines (Fig. 8A).

The cluster analysis discriminated the germplasm lines on the basis of genotyping of 136 SSR markers and placed the genotypes into different clusters which corresponded with the studied antioxidant traits. The unweighted-neighbour joining tree differentiated the genotypes into 4 different clusters (Fig. 8B ). The Cluster for Subpopulation 4 was differentiated from $\mathrm{SP}_{2}$ by the presence of germplasm lines containing high antioxidants in it while moderate to high containing genotypes were in the subpopulation 2. The green coloured portion of the tree is designated as SP4 while blue for SP2. The very poor antioxidants containing germplasm lines were in the subpopulation 3 depicted in red colour in the tree. Majority of the germplasm present in the subpopulation 1 were poor to medium in antioxidant content and shown in pink colour. The germplasm lines with admix type of population are depicted in black color in the neighbour joining tree neighbour joining tree neighbour joining tree (Fig. 8B).

\section{Marker-trait association for antioxidant compounds in rice}

Marker-trait associations was computed for 6 antioxidant compounds by using Generalized Linear Model (GLM) and Mixed Linear Model (MLM/ K+Q model)) in the TASSEL 5 software. The marker-trait association values were compared at less than $1 \%$ error i.e. $99 \%$ confidence $(p<0.01)$. A total of 57 and 23 significant marker-trait associations were detected for 5 antioxidant compounds by GLM and MLM, respectively at $p<0.01$. The range for marker $R^{2}$ values was from 0.0477 to 0.159 by GLM while 0.0607 to 0.1169 detected by Mixed Linear Model (Supplementary Table 3; Supplementary Table 4). A total of 15 significant marker-trait associations were detected by both the models for 5 antioxidant compounds present in the seed at $p<0.01$ (Fig. $9 \mathrm{~A}$ ). Significant association of 5 SSR markers with TAC; 3 with SOD, TFC; 2 with GO, and ABTS were detected. Five antioxidant compounds present in the studied germplasm lines showed higher marker $R^{2}(>0.1)$ with low $p(<0.01)$ values in the associations study includes SOD with RM405 and G0 with RM3701 (Table 5; Fig. $9 A$ ). The Q-Q plot also confirmed the association of these markers with the associated antioxidant traits in rice (Fig. 9B).

Four markers namely RM440, RM5638, RM253 and RM5626 showed significant associations with compound, TAC detected by GLM and MLM models at $p<0.01$ showing > 0.05 marker $R^{2}$ value. The QTLs controlling anthocyanin content in these genotypes are detected to be located markers RM440, RM5638, RM253 and RM5626 at 92.7, 86, 37 and 99 cM on the chromosome 5, 1, 6 and 3, respectively. Three markers namely RM582, RM467 and RM405 located at $66.4,46.8$ and $28.6 \mathrm{cM}$ positions on chromosome 1, 10 and 5, respectively were associated with the compound, SOD. TFC content was detected to be associated with markers RM 3701, RM235 and RM494 present at 45.3, 101.8 and 124.4 cM on chromosome 1, 11 and 12, respectively. The QTLs for ABTS showed significant associations with RM3701 and RM235 on chromosome 1 and 11, respectively. The marker RM216 showed association with SOD at very low p-value and high marker $\mathrm{R}^{2}$ value of $>0.10618$ analyzed by the GLM only. The QTLs for antioxidant compound, $\mathrm{OZ}$ showed significant associations with RM3701 and RM502 on chromosome 1 and 8, respectively (Table 5; Fig. 9A). The Q-Q plot also confirmed the associations of these markers with the estimated antioxidant compounds in rice (Fig. 9).

Association mapping study for antioxidant compounds in rice seeds identified co localization of QTLs controlling antioxidant compounds in rice. It is observed that same marker showed significant associations with different antioxidant compounds in rice by both the models (Table...). Significant associations of marker RM3701 with antioxidant compounds GO, TFC, and ABTS present in the germplasm lines were detected. In addition, it was also detected association of RM235 with compounds TAC, TFC, and ABTS by both the models at $<1 \%$ error and $p<0.01$ (Table 5 ). While considering marker association analyzing by GLM, the marker RM494 showed association with both carotenoids and TFC. In addition, RM494 was associated with both SOD and TFC content analyzed by MLM.

\section{Discussion}

The genotypes shortlisted for antioxidants mapping showed variation from each other with respect to 6 antioxidant compounds (Supplementary Table 1; Table 1). Also, few compounds showed higher correlation values among themselves. This provides enough clues for improvement of the antioxidant compounds through the correlated compounds based on the coefficients of the correlations and the availability of higher genetic variations for the antioxidants in the population (Table 1; Table 4). Earlier reports of high variations for antioxidants were also published by few researchers ${ }^{17,43,53,54,55}$. The 
available diversity in the population based on 136 markers data and 6 antioxidants showed clear cut groups in the studied population (Table 2). A moderate to high PIC value coupled with better informative markers in the studied population will be useful for improvement of antioxidants breeding program. The Jayapur tract of Odisha, known for secondary centre of origin of rice, germplasms from this tract has also been included in this study. Also, the shortlisted germplasm lines used as materials in this study were collected from the states known for their rich rice genetic diversity ${ }^{43}$.

The genotypes rich in multiple antioxidant compounds were identified in Ac. 44646, Ac. 44594 and Ac. $44595 ; 7$ in Ac. 43660 , and Ac. 20282 and 6 in Ac. 43738, Ac. 43660, and Ac. 44592. These germplasm lines will be good source materials in the antioxidant improvement programs (Table 1; Supplementary Table 2). Therefore, it is expected that breeding program with inclusion of parental lines from this population will be effective for antioxidants improvement. Structure analysis categorized the population into 4 subpopulations showing different Fst values supported the availability of linkage disequilibrium groups in the population. Detection of a low alpha value and existence of many genetic admix types germplasm lines in the population indicated that the antioxidants content evolved from a single source initially during evolution of the trait. Different antioxidant compounds were subsequently formed different admix genotypes with different ancestry value during evolutionary process. A good correspondence of genetic structure and different traits was previously published by many researchers $55,56,43$. Additionally, publications on phenotype of various traits and structure correlation have been published by many workers $51,52,57,58,59,60,61$.

Five antioxidant compounds were found to be associated with 12 SSR markers analyzed by both GLM and MLM approaches (Table 5). The markers association detected by both the models at $p<0.01$ and low ' $p$ 'value are considered to be very robust and useful markers for improvement program. The strongly associated SSR markers namely RM440, RM235, RM5638, RM253 and RM5626 for TAC; RM582 and RM467 for SOD; RM 3701 , RM235 and RM494 for TFC; RM3701 and RM235 for ABTS; RM3701 and RM502 for GO will be useful markers for selection of antioxidant compounds (Table 5). The Q-Q plot also confirmed the associations of these markers with the antioxidant compounds in rice (Fig. 9B).

The QTLs for anthocyanin and proanthocyanin content in rice was reported by earlier researchers $23,35,39,62$. In the present investigation, the QTLs for total anthocyanin content were detected on chromosome 1, 3, 5 and 12. The QTLs on chromosome 1 and 3 were at position $86 \mathrm{cM}$ and $99 \mathrm{cM}$, respectively. The genes, $q A N C 3$ and $q P A C 12-2$ reported by Xu et al. ${ }^{39}$ were at the same position as in the present investigation. Therefore, these two QTLs were validated in our study. However, another two QTLs located on chromosome 1 and 5 detected in this investigation are not reported by earlier researchers. These two QTLs may be new loci which affect TAC in rice and designated as qTAC1.1 and qTAC5.1. Three markers namely RM582, RM405 and RM467 showed association with SOD and located on chromosome 1, 5 and 10 at $66.4,28.6$ and $46.8 \mathrm{cM}$, respectively. The QTLs for SOD located in these locations were not reported in earlier mapping studies. These QTLs designated as qSOD1.1, qSOD5.1 and qSOD10.1 may be new loci controlling the SOD activities in rice seeds. Total flavonoids content (TFC) is detected to be associated with 3 regions on the chromosome 6, 11 and 12. Earlier publication showed the presence of QTLs on chromosome $4,7,8,9$ and $10^{10}$. The main flavonoids structural genes located on chromosome 11 for $\mathrm{CHS}^{62}$; on chromosome 3 for $\mathrm{CHI}^{63}$; on chromosome 4 for $\mathrm{F} 3 \mathrm{H}^{64}$; on Chromosome 1 for DFR ${ }^{65}$ and $\mathrm{ANS}^{66}$. The gene CHS on chromosome 11 was at $3.3 \mathrm{cM}$. We detected at $45.3 \mathrm{cM}$. Therefore, all these 3 detected QTLs which affect total flavonoids are new loci and designated as qTFC 6.1, qTFC11.1 and qTFC12.1.

Food containing $\mathrm{Y}$-oryzanol $(\mathrm{OZ})$ is well recognized for health benefit. This is a mixture of several compounds present in the rice bran layer. $\mathrm{Y}$-oryzanol content in this study showed significant association with markers on the chromosomes 8 and 11. However, QTLs previously reported by earlier workers reported on the chromosome 1, 5 and 9 in Asominori/IR24 RILs ${ }^{42}$. But they detected another 5 QTLs for OZ in the backcross lines of Sasanishiki/Habataki//Sasanishiki. These two new loci detected in this investigation are new loci controlling y-oryzanol and designated as qOZ8.1 and qOZ11.1. The QTLs for ABTS showed significant associations with RM3701 and RM235 on chromosome 11 and 12, respectively. The candidate gene controlling ABTS and present on the chromosome 11 is not reported by earlier researchers. Hence, the detected QTL for ABTS on chromosome 11 at $45.3 \mathrm{cM}$ position is a new locus controlling the trait and designated as $q A C 11.1$. However, the other detected association for the trait on chromosome 12 is located at $26.1 \mathrm{Mb}$ position. In earlier mapping publication reported the gene on the chromosome 12 at $25.2 \mathrm{Mp}$ position ${ }^{38}$. As our detected QTL position for ABTS is close to the reported QTL qAC12, this QTL is validated in our mapping population and can be useful in the marker-assisted breeding for ABTS improvement.

Two markers were observed to be associated with more than one antioxidant traits analyzed by both the models at $<1 \%$ error and $p<0.01$. Marker RM 3701 showed associations with GO, TFC, and ABTS present in the germplasm lines. Also, RM235 was associated with traits, TAC, TFC, and ABTS by both the models (Table 5). These observations indicated the close location of the candidate genes and simultaneous inheritance of these QTLs. Hence, simultaneous improvement of both these antioxidant traits will be effective. In recent publications also suggested easy improvement of the co-localized genes controlling various traits in rice $6,51,61,67$. Results of the present investigation showed that association mapping is an effective method to find more potential loci for antioxidant compounds and antioxidant capacity in rice. The detected loci will further be fine mapped for application in maker-assisted breeding for improvement of antioxidants in rice.

\section{Conclusion}

Consumption rice containing higher content of antioxidants has many health benefits. Donor lines rich in antioxidants compounds with $>3$ antioxidant compounds were identified in higher level of antioxidants. The germplasm lines Ac. 44592, Ac. 44646, Ac. 44595, Ac. 43660, Ac. 43738, Ac. 43660, and Ac. 43669 were indentified for rich germplasm lines carrying more than 3 antioxidants. Five antioxidant traits viz., superoxide dismutase, flavonoids, anthocyanins, $y$-oryzanol and ABTS were mapped in the panel population using 136 SSR markers through association mapping. Wide variations were observed for the six antioxidants content in the population. The population was classified into 4 genetic structure groups by the structure analysis. The existence of linkage disequilibrium for the antioxidant traits was established based on the population's fixation indices. The population was classified into four subpopulations which showed fair degree of correspondence with the antioxidants content. A total of 14 significant marker-trait associations for antioxidants were detected of which 3 QTLs namely $q A N C 3, q P A C 12-2$ for anthocyanin content and $q A C 12$ for ABTS activity were validated in the population.

Page $7 / 30$ 
These 3 QTLs are useful in the marker-assisted breeding programs. Eleven putative QTLs such as qTAC1.1 and qTAC5.1 for anthocyanin content; qSOD1.1, qSOD5.1 and qSOD10.1 for SOD; qTFC6.1, qTFC11.1 and qTFC12.1 for TFC; qOZ8.1 and qOZ11.1 for y-oryzanol and $q A C 11.1$ for ABTS were detected to be novel loci. Co-localization of the QTLs detected for OZ11.1, TFC11.1 and AC11.1 regulating Y-oryzanol, flavonoid and anthocyanin content, respectively while PAC12.2 for anthocyanin content remained closer to TFC12.1 for flavonoid content. These strongly associated QTLs will be useful in the antioxidants improvement programs in rice.

\section{Declarations}

Ethics approval and consent to participate: The authors declare that this study complies with the current laws of the country in which the experiments were performed.

Consent for publication: Not applicable

Availability of data and material: The data generated or analyzed in this study are included in this article.

Competing interest: The authors declare no conflicts of interest

Funding: No externally aided funding was utilized for this research work

Authors contribution: SK Pradhan and E Pandit conceived the study. SR Barik, R Bastia, A Behera, A Moharana, and E Pandit conducted the genotyping work. P Sanghmitra, R Bastia, SP Mohanty, N Basak and SK Pradhan performed the phynotyping work. SR Barik analyzed the data. SK Pradhan and P Sanghamitr wrote the manuscript. All the authors read and approved the final version.

\section{Acknowledgement}

The authors acknowledge the support of Director, ICAR-National Rice Research Institute, Cuttack for providing all the necessary facilities including the funding for conducting the experiment.

\section{References}

1. Alsan, M., Bloom, D.E., Canning, D. \& Jamison, D. The Consequences of Population Health for Economic Performance," PGDA Working Papers 1306, Program on the Global Demography of Aging (2006).

2. Shridhar, G., Rajendra, N., Murigendra, H., Shridevi, P., Prasad, M., Mujeeb, M.A., Arun, S., Neeraj, D., Vikas, S., Suneel, D. \& Vijay, K. Modern Diet and its Impact on Human Health. J Nutr Food Sci 5, 6. https://doi.org/10.4172/2155-9600.1000430 (2015).

3. Descalsota-Empleo, G.I., Noraziyah, A.A.S., Navea, I.P., Chung, C., Dwiyanti, M.S., Labios, R.J.D., et al.Genetic Dissection of Grain Nutritional Traits and Leaf Blight Resistance in Rice. Genes 10(1). https:// doi.org /10.3390/genes10010030 (2019).

4. Singh, S.P., Gruissem, W. \& Bhullar, N.K. Single genetic locus improvement of iron, zinc and $\beta$-carotene content in rice grains. Sci Rep 7, 6883 (2017).

5. Garg, M., Sharma, N., Sharma, S., Kapoor, P., Kumar, A., Chunduri, V. \& Arora, P. Biofortified crops generated by breeding; agronomy; and transgenic approaches are improving lives of millions of people around the world. Front Nutr 5, 12 (2018).

6. Pradhan, S.K., Pandit, E., Pawar, S., Bharati, B., Chatopadhyay, K., Singh, S., Dash, P. \& Reddy, J.N. Association mapping reveals multiple QTLs for grain protein content in rice useful for biofortification. Mol Genet Genom 294(4), 963-983. https://doi.org/10.1007/s00438-019-01556-w (2019a).

7. Ashokkumar, K., Govindaraj, M.,Karthikeyan, A., Shobhana, V.G. \& Warkentin, T.D. Genomics-Integrated Breeding for Carotenoids and Folates in Staple Cereal Grains to Reduce Malnutrition. Front. Genet 11,414. https://doi.org/10.3389/fgene.2020.00414 (2020).

8. Pradhan, S.K., Pandit, E., Pawar, S., Naveenkumar, R., Barik, S.R., Mohanty, S.P., Nayak, D.K.,Ghritlahre, S.K., Rao, D.S., Reddy, J.N. \& Patnaik, S.S.C.Linkage disequilibrium mapping forgrain Fe and Zn enhancing QTLs useful for nutrient dense rice breeding. BMC Plant Bio/20(1),57. DOI: 10.1186/s12870-0202262-4(2020).

9. Zhu, C., Kobayashi, K., Loladze, I., Zhu, J., Jiang, Q., Xu, X., Liu, G., Seneweera, S., Ebi, K.L., Drewnowski, A., Fukagawa, N.K. \& Ziska, L.H. Carbon dioxide $\left(\mathrm{CO}_{2}\right)$ levels this century will alter the protein, micronutrients, and vitamin content of rice grains with potential health consequences for the poorest ricedependent countries. Sci Adv 4, eaaq1012 (2018).

10. Shao, Y., Jin, L., Zhang, G., Lu, Y., Shen, Y. \&Bao, J. Association mapping of grain color, phenolic content, flavonoid content and antioxidant capacity in dehulled rice. TheorApp/ Genet 122, 1005-1016. https://doi.org/10.1007/s00122-010-1505-4 (2011).

11. Shao, Y. \& Bao, J. Polyphenols in whole rice grain: Genetic diversity and health benefits. Food Chem 180, 86-97 (2015).

12. Panda, S.K. Assay Guided Comparison for Enzymatic and Non-Enzymatic Antioxidant Activities with Special Reference to Medicinal Plant. In book: Antioxidant Enzyme (Ed)El-Missiry AM Chapter 15, 381-400 https://doi.org/10.5772/50782 (2012).

13. Govindaraj, M., Masilamani P.V., Albert, A.\&Bhaskaran, M. Role of antioxidant in seed quality- A review. Agric.Rev. 38(3), 180-190(2017).

14. Ferreira, I.C.F.R. \& Abreu, R.M.V. Stress oxidativo, antioxidantes efitoquímicos. Bioana'lise 2, 32-39 (2007).

15. Rossatto, T., de- Amaral, M.N., Benitez, L.C., Vighi, I.L., Braga, E., de Magalhães, J., Maia A.M.M.\& da Silva, P. L. Gene expression and activity of antioxidant enzymes in rice plants, cv. BRS AG, under saline stress. Physiol. Mol. Biol. Plants 23(4), 865-875(2017). https://doi.org/ 10.1007/s12298-017-0467-2

16. Islam, M., Begum, H., Ali, M., Kamruzzaman, M., Hoque, S. \& Hoque, M. DNA fingerprinting and genetic diversities in some Bangladeshi aus rice (Oryza sativa L.) genotypes. SAARC J Agric 15(1),123-37 (2017). 
17. Sanghamitra, P., Sah, R.P., Bagchi, T.B., Sharma, S.G., Kumar, A., Munda, S. \& Sahu, R.K. Evaluation of variability and environmental stability of grain quality and agronomic parameters of pigmented rice (O. sativa L.) J Food Sci Technol 55, 879-890 (2018).

18. Mbanjo, E.G.N., Kretzschmar, T., Jones, H., Ereful, N., Blanchard, C., Boyd, L.A. \& Sreenivasulu, N. The Genetic Basis and Nutritional Benefits of Pigmented Rice Grain. Front Genet 11, 229. https://doi.org/10.3389/fgene.2020.00229 (2020).

19. Xu, Feifei., Jinsong, Bao., Tae-Sung, Kim. \& Yong-Jin, Park. Genome-wide Association Mapping of Polyphenol Contents and Antioxidant Capacity in Whole-Grain Rice J. Agric. Food Chem. 2016, 64, 22, 4695-4703 (2016).20.Zhai, S.N., Xia, X.C. \& He, Z.H. Carotenoids in Staple Cereals: Metabolism, Regulation, and Genetic Manipulation. Front Plant Sci 7, 1197. https://doi.org/10.3389/fpls.2016.01197 (2016).

20. Ashraf, H., Murtaza, I., Nazir, N., Wani, A.B., Naqash, S. \& Husaini, A.M. Nutritional profiling of pigmented and scented rice genotypes of Kashmir Himalayas. J. Pharmacogn Phytochem 6, 910-916 (2017).

21. Petroni, K., Landoni, M., Tomay, F. \& Calvenzani, V. Proximate composition, polyphenol content and anti-inflammatory properties of white and pigmented Italian rice varieties. Univ J Agric Res 5, 312-321. https://doi.org/10.13189/ujar.2017.050509 (2017).

22. Furukawa, T., Maekawa, M., Oki, T., Suda, I., lida, S., Shimada, H., Takamure, I., Kadowaki, K. The Rc and Rd genes are involved in proanthocyanidin synthesis in rice pericarp. Plant J Cell Mol Biol 49(1), 91-102 (2006).

23. Sweeney, M.T., Thomson, M.J., Pfeil, B.E. \& Mccouch, S. Caught red-handed: Rc encodes a basic Helix-Loop-Helix protein conditioning red pricarp in rice. Plant Cell 18(2), 283-294 (2006).

24. Dong, Y.J., Xu, J.L., Xiao, K, Zhang, Y.J., Zhang, J.Z., Luo, L.J. \& Mastuo, M, Genomic regions associated with the degree of red coloration in pericarp of rice (Oryza sativa L.). J Cereal Sci 48(2), 556-560 (2008).

25. Yoshimura, A., Ideta, O. \& Iwata, N. Linkage map of phenotype and RFLP markers in rice. Plant Mol Bio/35, 49-60 (1997).

26. Wang, C.X. \& Shu, Q.Y. Fine mapping and candidate gene analysis of purple pericarp gene Pb in rice (Oryza sativa L.). Chin Sci Bull 52, $3097-3104$ (2007).

27. Rahman, M.M., Lee, K.E., Lee, E.S., Matin, M.N., Lee, D.S., Yun, J.S., et al. The genetic constitutions of complementary genes Pp and Pb determine the purple color variation in pericarps with cyanidin-3-0-glucoside depositions in black rice. J Plant Bio/56, 24-31. https://doi.org/10.1007/s12374-012-00439 (2013).

28. Ham, T., Kwon, S.W., Ryu, S. \& Koh, H. Correlation analysis between grain color and cyanidin-3-glucoside content of rice grain in segregate population. Plant Breed Biotechno/3, 160-166. https://doi.org/10.9787/pbb.2015.3.2.160 (2015).

29. Kim, B.G., Kim, J.H., Min, S.Y., Shin, K.H., Kim, J.H., Kim, H.Y., Ryu, S.N. \& Ahn, J.H. Anthocyanin content in rice is related to repeat protein from Medicago truncatula is necessary for tissue-specific anthocyanin and proanthocyanidin biosynthesis but not for trichome development. Plant Physio/151(3), 11141129 (2007)

30. Sun, X., Zhang, Z., Chen, C., Wu, W., Ren, N., Jiang, C., et al. The C-S-A gene system regulates hull pigmentation and reveals evolution of anthocyanin biosynthesis pathway in rice. J Exp Bot 69, 1485-1498. https://doi.org/10.1093/jxb/ ery001 (2018).

31. Sakamoto, W., Ohmori, T., Kageyama, K., Miyazaki, C., Saito, A. , Murata, M., Noda, K. \& Maekawa, M. The Purple leaf (PI) locus of rice: the Plw allele has a complex organization and includes two genes encoding basic helix-loop-helix proteins involved in anthocyanin biosynthesis. Plant Cell Physiol 42 , 982991 (2001).

32. Maeda, H., Yamaguchi, T., Omoteno, M., Takarada, T., Fujita, K., Murata, K., et al. Genetic dissection of black grain rice by the development of a near isogenic line. Breed Sci 64, 134-141. https://doi.org/10.1270/jsbbs.64.134 (2014).

33. Oikawa, T., Maeda, H., Oguchi, T., Yamaguchi, T., Tanabe, N., Ebana, K., et al. The birth of a black rice gene and its local spread by introgression. Plant Cell 27, 2401-2414. https://doi.org/10.1105/tpc.15.00310(2015).

34. Yang, X., Xia, X., Zeng, Y., Nong, B., Zhang, Z., Wu, Y., et al. Identification of candidate genes for gelatinization temperature, gel consistency and pericarp color by GWAS in rice based on SLAF-sequencing. PLOS ONE 13(5), e0196690 https://doi.org/ 10.1371/journal. pone.0196690(2018).

35. Roy, S. C. \& Shil, P. Black Rice Developed Through Interspecific Hybridization (O. sativa x O. rufipogon): Origin of Black Rice Gene from Indian Wild RiceBioRxiv.12.25,423663(2020).https://doi.org/10.1101/2020.12.25.423663.

36. Tan, Y.F., Sun, M., Xing, Y.Z., Hua, J.P., Sun, X.L., Zhang, Q.F., et al. Mapping quantitative trait loci for milling quality, protein content and color characteristics of rice using a recombinant inbred line population derived from an elite rice hybrid. Theor Appl Genet103, 1037-1045. https://doi.org/10.1007/s001220100665 (2001).

37. Jin, L., Xiao, P., Lu, Y., Shao, Y.F., Shen, Y. \& Bao, J.S. Quantitative trait loci for brown rice color, total phenolics and, flavonoid contents and antioxidant capacity in rice grain. Cereal Chem $86,609-615$ (2009).

38. Shao, Y., Tang, F., Huang, Y., Xu, F., Chen, Y., Tong, C., Chen, H. \& Bao, J. Analysis of genotype x environment interactions for polyphenols and antioxidant capacity of rice by association mapping. J Agric Food Chem 62(23), 5361-8. https://doi.org/10.1021/jf500951e (2014).

39. Xu, Feifei., Jinsong, Bao., Tae-Sung, Kim. \& Yong-Jin, Park. Genome-wide Association Mapping of Polyphenol Contents and Antioxidant Capacity in Whole-Grain Rice J. Agric. Food Chem. 2016, 64, 22, 4695-4703 (2016).

40. Xu, T.Y., Sun, J., Chang, H.L., Zheng, H.L., Wang, J.G., Liu, H.L., Yang, L.M., Zhao, H.W. \& Zou, D.T. QTL mapping for anthocyanin and proanthocyanidin content in red rice. Euphytica 213, 243 https://doi.org/10.1007/s10681-017-2035-9 (2017).

41. Zainal-Abidin, R.A., Abu-Bakar, N., Sew, Y.S., Simoh, S. \& Mohamed-Hussein, Z.A. Discovery of Functional SNPs via Genome-Wide Exploration of Malaysian Pigmented Rice Varieties. Int J Genom, 4168045. https://doi.org/10.1155/2019/4168045 (2019).

42. Kato, T., Matsukawa T. \&HoribataA. Quantitative trait loci responsible for the difference in Y-oryzanol content in brown rice between japonica-type and indica-type rice cultivars. Plant Prod. Sci.20, 459-466 (2017). 
43. Sahoo, S., Sanghamitra, P., Nanda, N., Pawar, S., Pandit, E., Bastia, R., Muduli, K.C. \& Pradhan, S.K. Association of molecular markers with physiobiochemical traits related to seed vigour in rice. Physiol Mol Biol Plants 26(10), 1989-2003. https://doi.org/ 10.1007/s12298-020-00879-y(2020).

44. Zhu, Q., Yu, S., Zeng, D., Liu, H., Wang, H., Yang, Z., Xie, X., Shen, R., Tan, J., Li, H., Zhao, X., Zhang, Q., Chen, Y., Guo, J., Chen, L. \& Liu, Y.G. Development of "Purple Endosperm Rice" by engineering anthocyanin biosynthesis in the endosperm with a high-efficiency transgene stacking system. Mol. Plant.10, 918-929 (2017).

45. Wickert, E., Schiocchet, M.A., Noldin, J.A., Raimondi, J.V., De Andrade, A., Scheuermann, K.K., et al. Exploring variability: New Brazilian varieties SCS119 Rubi and SCS120 Onix for the specialty rices market. Open J Genet 4, 157-165. https://doi.org/ 10.4236/ojgen.2014.42016 (2014).

46. Waiyawuththanapoom, P., Waiyawuththanapoom, W., and Tirastittam, P. (2015). Social media as a channel for Thailand's Rice Berry Product. Int. J. Econ. Manag. Eng. 9, 904-907.

47. Bhuiyan,M.A.R.,Narimah, M.K., Rahim, H.A., Abdullah, M.Z.\&Wickneswari, R. Transgressive variants for red pericarp grain with high yield potential derived from OryzarufipogonxOryza sativa: field evaluation, screening for blast disease, QTL validation and background marker analysis for agronomic traits. Field Crops Res. 121, 232-239(2011). https:// doi.org /10.1016/j.fcr.2010.12.012.

48. Arbelaez, J.D., Moreno, L.T., Singh, N., Tung, C.W., Maron, L.G., Ospina, Y., et al. Development and GBS-genotyping of introgression lines (ILs) using two wild species of rice. O. meridionalis and 0 . rufipogon, in a common recurrent parent, 0 . sativa cv. Curinga. Mol. Breed. 35,81 . https://doi.org/10.1007/s11032-015-0276-7 (2015).

49. Roy,S. C.\&Shil,P.Black Rice Developed Through Interspecific Hybridization (O. sativa x O. rufipogon): Origin of Black Rice Gene from Indian Wild RiceBioRxiv.12.25,423663(2020).https://doi.org/10.1101/2020.12.25.423663.

50. Yu, J., Pressoir, G., Briggs, W.H., Vroh Bi, I., Yamasaki, M., Doebley, J.F., Mc Mullen, M.D., Gaut, B.S., Nielsen, D.M., Holland, J.B., Kresovich, S., Buckler, E.S. A unified mixed model method for association mapping that accounts for multiple levels of relatedness. Nature Genetics 38,203-208. https://doi.org/10. 1038/ ng1702 (2006).

51. Pandit, E., Tasleem, S., Barik, S.R., Mohanty, D.P., Nayak, D.K., Mohanty, S.P., Das, S. \& Pradhan, S.K. Genome-wide association mapping reveals multiple QTLs governing tolerance response for seedling stage chilling stress in indica rice, Front Plant Sci 8, 552. https://doi.org/10.3389/fpls.2017.00552(2017)

52. Pawar, S., Pandit, E., Mohanty, I.C., Saha, D.\& Pradhan, S.K. Population genetic structure and association mapping for iron toxicity tolerance in rice. PLOS ONE 16(3), e0246232(2021). https://doi.org/10.1371/journal.pone.0246232.

53. Oselebe, H. O., Ogah, O,Odo, M. I,\&Ogbu, K.I. Determination of Phytochemical and Antioxidant Properties of Some Rice Varieties and Hybrids Grown in Ebonyi State, Nigeria.Nig J. Biotech. 26, 60-67 (2013)

54. Goufo, P.\&Trindade, H. Rice antioxidants: phenolic acids, flavonoids, anthocyanins, proanthocyanidins, tocopherols, tocotrienols, $\mathrm{Y}$-oryzanol, and phytic acid. Food Sci.Nutr.2(2),75-104(2014). https:// doi: 10.1002/fsn3.86.

55. Sanghamitra, P., Bagchi, T. B., Sharma, S.G., Sarkar, S. \& Basak, N. Characterization of red and purple-pericarp rice (Oryza sativa L) based on physicochemical and antioxidative properties of grains. Oryza 54, 57-64 (2017).

56. Pradhan, S.K., Pandit, E., Pawar, S., Bharati, B., Chatopadhyay, K., Singh, S., Dash, P. \& Reddy, J.N.Association mapping reveals multiple QTLs for grain protein content in rice useful forbiofortification. Mol Genet Genom 294(4),963-983. doi: 10.1007/s00438-019-01556-w(2019b).

57. Huang, X., Zhao, Y., Wei, X., Li, C., Wang, A., Zhao, Q., Li, W., Guo, Y., Deng, L., Zhu, C., Fan, D., Lu, Y., Weng, Q., Liu, K., Zhou, T., Jing, Y., Si, L., Dong, G., Huang, T., Lu, T., Feng, Q., Qian, Q., Li, J., Han, B. Genome-wide association study of flowering time and grain yield traits in a worldwide collection of rice germplasm. Nature Genetics 44(1), 32-39. doi: 10.1038/ng.1018. PMID: 22138690(2011).

58. Zhang, Y., Zou, M. \& De, T. Association analysis of rice cold tolerance at tillering stage with SSR markers in japonica cultivars in Northeast China. Chin.J . Rice Sci.26, 423-430(2012).

59. Huang, Li., He, H., Chen, H., Ren, X., Chen, Y., Zhou, X., Xia, Y., Wang, X., Jiang, X., Liao, B., Jiang, H. Quantitative trait locus analysis of agronomic and quality-related traits in cultivated peanut (Arachishypogaea L.) Theoretical and Applied genetics 128, 1103-1115(2015).

60. Pradhan, S.K., Barik, S.R., Sahoo, A., Mohapatra, S., Nayak, D.K., Mahender, A., Meher, J., Anandan, A. \& Pandit, E. Population structure, genetic diversity and molecular marker-trait association analysis for high temperature stress tolerance in rice. PLoS ONE 11 (8),123.DOI: https://doi. org/10.1371/ journal.pone. 0160027 (2016).

61. Pradhan, S.K., Pandit, E., Pawar, S., Naveenkumar, R., Barik, S.R., Mohanty, S.P., Nayak, D.K., Ghritlahre, S.K., Rao, D.S., Reddy, J.N. \& Patnaik, S.S.C. Linkage disequilibrium mapping for grain Fe and Zn enhancing QTLs useful for nutrient dense rice breeding. BMC Plant Biol $20(1), 57$. https://doi.org/10.1186/s12870-020-2262-4 (2020).

62. Shao, Y., Jin, L., Zhang, G., Lu, Y., Shen, Y. \& Bao, J. Association mapping of grain color, phenolic content, flavonoid content and antioxidant capacity in dehulled rice. Theor App/ Genet 122, 1005-1016. https://doi.org/10.1007/s00122-010-1505-4 (2011).

63. Druka A, Kudrna D, Rostoks N, Brueggeman R, von Wettstein D, Kleinhofs A (2003) Chalcone isomerase gene from rice (Oryza sativa) and barley (Hordeum vulgare): physical, genetic and mutation mapping. Gene 302(1-2):171-178. https://doi.org/10.1016/S0378-1119(02)01105-8

64. Shih, C.H., Chu, H., Tang, L.K., Sakamoto, W., Maekawa, M., Chu, I.K., Wang, M.\& Lo, C. Functional characterization of key structural genes in rice flavonoid biosynthesis. Planta 228(6), 1043-54(2008). https://doi.org/10.1007/s00425-008-0806-.

65. Furukawa, T., Maekawa, M., Oki, T., Suda, I., lida, S., Shimada, H., Takamure, I. et al(2007). The Rcand Rd genes are involved in proanthocyanidin synthesis in rice pericarp. Plant J. 49, 91-102.

66. Reddy, A.M, Reddy, V. S., Scheffler, B. E., Wienand, U., Reddy, A. R.(2007). Novel transgenic rice overexpressing anthocyanidin synthase accumulates a mixture of flavonoids leading to an increased antioxidant potential. Metabolic Engineering, 9, 95-111. https://doi.org/10.1016/j.ymben.2006.09.003

Page $10 / 30$ 
67. Pradhan, S.K., Barik, S.R., Sahoo, A., Mohapatra, S., Nayak, D.K., Mahender, A., Meher, J., Anandan, A. \& Pandit, E. Population structure, genetic diversity and molecular marker-trait association analysis for high temperature stress tolerance in rice. PLoS ONE 11 (8),123. https://doi. org/10.1371/ journal. pone. 0160027 (2016).

68. Davis, B.H. Carotenoids. In: Goodwin TW (ed) Chemistry and biochemistry of plant pigments, 2nd edn. Academic Press Inc, London, pp 38-165(1976).

69. Madamanchi, N.R., Donahue, J.L., Cramer, C.L., Alscher, R.G. \&Pedersen, K. Differential response of Cu, Zn SOD in two pea cultivars during a short term exposure to SO2. Plant Mol Biol 26, 95-103 (1994).

70. Fuleki, T. \& Francis, F.J. Quantitative methods for anthocyanins, extraction and determination of total anthocyanin in cranberries. J Food Sci $33,72-77$ (1968).

71. Bucci, R., Magri, A.D., Magri, A.L. \&Marini, F. Comparison of three spectrophotometric methods for the determination of gammaoryzanol in rice bran oil. Anal Bioanal Chem 375(8),1254-1259 (2003).

72. Eberhardt, M.V., Lee, C.Y. \& Liu, R.H. Antioxidant activity of fresh apples. Nature 405, 903-904(2000).

73. Serpen, A., Gokmen, V., Pellegrini, N. \& Fogliano, V. Direct measurement of the total antioxidant capacity of cereal products. J Cereal Sci 48 , 816-820. https://doi.org/10.1016/j.jcs.2008.06.002 (2008).

74. Murray, M.G. \& Thompson, W.F. Rapid isolation of high molecular weight plant DNA. Nucleic Acids Res 8, 4321-4325. PMID: 7433111(1980).

75. Barik, S.R., Pandit, E., Pradhan, S.K., Singh, S.\&Mohapatra, T. QTL mapping for relative water content trait at reproductive stage drought tolerance in rice. Ind. J.Genet.Plant Breed.78 (4), 401-408(2018).

76. Barik, S.R., Pandit, E., Pradhan, S.K., Mohanty, S.P.\&Mohapatra, T. Genetic mapping of morpho-physiological traits involved during reproductive stage drought tolerance in rice. PLoS ONE14(12), e0214979(2009). https://doi.org/10.1371/ journal.pone.0214979

77. Pradhan, S.K., Pandit, E., Pawar, S., Baksh, S.Y., Mukherjee, A.K. \& Mohanty, S.P. Development of flash-flood tolerant and durable bacterial blight resistant versions of mega rice variety 'Swarna' through marker-assisted backcross breeding. Scientific reports 9,12810https://doi.org/10.1038/s41598-019-49176$\mathrm{z}(2019 \mathrm{~b})$.

78. Liu, K. \&Muse, S.V. Power Marker: an integrated analysis environment for genetic marker analysis. Bioinformatics 21(9), 2128-2129(2005).

79. Pritchard, J.K., Stephens, M. \& Donnelly, P. Inference of population structure using multilocus genotype data. Genetics 155(2), 945-59 (2000).

80. Evanno, G., Regnaut, S. \& Goudet, J. Detecting the number of clusters of individuals usingthe software STRUCTURE: A simulation study. Mol Ecol 14(8), 2611-2620. PMID: 15969739 (2005).

81. Earl,D.A. \&Vonholdt, B.M. Structure Harvester: a website and program for visualizing STRUCTURE output and implementing the Evannomethod.Conservation Genetics Resources 4, 359-361(2012).

82. Nei, M. Genetic distance between populations. American Naturalist 106, 283-292(1972).

83. Perrier, X. \& Jacquemoud-Collet, J.P. DARwin Software. http:// darwin. cirad.fr/darwin. (2006).

84. Pandit, E., Panda, R.K., Sahoo, A., Pani, D.R. \& Pradhan, S.K. Genetic relationship and structure analyses of root growth angle for improvement of drought avoidance in early and mid-early maturing rice genotypes. Rice Sci 27(2), 124-132 (2020).

85. Bradbury, P.J., Zhang, Z., Kroon, D.E., Casstevens, T.M., Ramdoss, Y. \& Buckler, E.S.TASSEL: Software for association mapping of complex traits in diverse samples. Bioinformatics Applications Note 23(19), 2633-2635. DOI: 10.1093/bioinformatics/btm308 (2007).

\section{Tables}

Table 1. Mean values of carotenoids, SOD, TAC, GO, TFC and ABTS antioxidants estimated from 120 genotypes present in the panel population 


\begin{tabular}{|c|c|c|c|c|c|c|c|c|}
\hline SI.No. & Kernel colour & Genotype/Vernacular name/Accession no. & Carotenoids & SOD & TAC & GO & TFC & ABTS \\
\hline 1 & White & AC5993 & 0.115 & 0.239 & 0.209 & 43.750 & 12.333 & 8.853 \\
\hline 2 & White & AC6221 & 0.423 & 0.101 & 0.159 & 47.375 & 13.333 & 8.952 \\
\hline 3 & White & AC6183 & 0.182 & 0.015 & 0.102 & 47.125 & 13.889 & 14.119 \\
\hline 4 & White & AC6170 & 1.165 & 0.176 & 0.090 & 52.250 & 13.333 & 11.063 \\
\hline 5 & White & AC6023 & 0.112 & 0.280 & 0.143 & 33.313 & 13.000 & 10.522 \\
\hline 6 & White & AC6172 & 0.297 & 0.181 & 0.225 & 34.125 & 13.444 & 7.569 \\
\hline 7 & White & AC6027 & 0.133 & 0.175 & 0.141 & 38.188 & 12.333 & 7.983 \\
\hline 8 & White & AC6007 & 0.287 & 0.192 & 0.027 & 32.125 & 13.111 & 7.983 \\
\hline 9 & White & AC9006 & 1.014 & 0.284 & 0.064 & 70.438 & 17.889 & 11.412 \\
\hline 10 & White & AC9021 & 0.444 & 0.199 & 0.083 & 76.313 & 22.000 & 11.769 \\
\hline 11 & Red & AC9028 & 0.776 & 0.216 & 0.250 & 87.500 & 45.556 & 36.976 \\
\hline 12 & White & AC9030 & 0.686 & 0.150 & 0.123 & 39.563 & 18.667 & 11.555 \\
\hline 13 & White & AC9035 & 0.262 & 0.196 & 0.117 & 49.500 & 17.667 & 11.698 \\
\hline 14 & Red & AC9038 & 0.371 & 0.241 & 0.459 & 28.438 & 47.000 & 41.341 \\
\hline 15 & White & AC9043 & 0.308 & 0.175 & 0.061 & 39.688 & 18.444 & 8.131 \\
\hline 16 & White & AC9044A & 0.713 & 0.221 & 0.048 & 49.938 & 17.556 & 15.906 \\
\hline 17 & Red & AC20920 & 1.264 & 0.312 & 0.325 & 54.125 & 43.889 & 26.061 \\
\hline 18 & Red & AC20907 & 0.919 & 0.308 & 0.551 & 64.750 & 52.444 & 26.501 \\
\hline 19 & White & AC20845 & 1.257 & 0.265 & 0.102 & 61.250 & 18.889 & 6.442 \\
\hline 20 & Red & AC20770 & 1.379 & 0.313 & 0.568 & 62.688 & 62.333 & 35.959 \\
\hline 21 & Red & AC20627 & 1.164 & 0.245 & 0.451 & 93.375 & 45.333 & 22.694 \\
\hline 22 & White & AC20686 & 0.968 & 0.290 & 0.073 & 43.188 & 21.778 & 4.539 \\
\hline 23 & White & AC20664 & 0.828 & 0.256 & 0.070 & 51.938 & 19.778 & 7.028 \\
\hline 24 & Red & AC20614 & 0.727 & 0.273 & 0.609 & 85.250 & 62.841 & 38.448 \\
\hline 25 & White & Jhagrikartik & 0.080 & 0.209 & 0.167 & 39.688 & 15.222 & 10.623 \\
\hline 26 & White & Dadghani & 0.411 & 0.206 & 0.130 & 51.875 & 16.000 & 12.606 \\
\hline 27 & White & Shayam & 0.455 & 0.196 & 0.170 & 58.313 & 19.333 & 12.677 \\
\hline 28 & White & Basumati-B & 0.091 & 0.177 & 0.124 & 55.750 & 20.667 & 15.935 \\
\hline 29 & Red & Bharati & 0.108 & 0.235 & 0.442 & 41.250 & 35.667 & 33.669 \\
\hline 30 & White & Joha & 0.094 & 0.248 & 0.155 & 41.688 & 17.000 & 11.402 \\
\hline 31 & Red & Adira-1 & 0.350 & 0.137 & 0.943 & 46.750 & 114.222 & 39.115 \\
\hline 32 & Red & Adira-2 & 0.511 & 0.094 & 0.901 & 54.313 & 80.111 & 38.316 \\
\hline 33 & Red & Adira-3 & 0.472 & 0.039 & 2.996 & 48.750 & 79.667 & 38.099 \\
\hline 34 & Red & PK6 & 0.217 & 0.112 & 1.168 & 46.125 & 62.222 & 33.091 \\
\hline 35 & Red & Vachaw & 0.388 & 0.078 & 1.568 & 47.563 & 54.111 & 39.317 \\
\hline 36 & Red & Kozhivalan & 0.476 & 0.007 & 0.684 & 51.500 & 67.667 & 27.279 \\
\hline 37 & Red & Marathondi & 0.479 & 0.059 & 0.501 & 45.188 & 45.556 & 35.626 \\
\hline 38 & Red & Ezhoml-2 & 0.234 & 0.035 & 0.801 & 46.688 & 85.667 & 33.512 \\
\hline 39 & Red & Jyothi & 0.437 & 0.062 & 0.901 & 56.750 & 58.889 & 31.916 \\
\hline 40 & Red & Kantakapura & 0.947 & 0.068 & 0.417 & 39.000 & 62.333 & 36.994 \\
\hline 41 & Red & Kantakaamala & 1.202 & 0.116 & 0.451 & 34.875 & 60.111 & 31.503 \\
\hline 42 & Red & Kapanthi & 0.989 & 0.177 & 0.451 & 10.813 & 41.444 & 41.757 \\
\hline 43 & White & Karpurkanti & 1.052 & 0.155 & 0.079 & 44.625 & 18.333 & 12.645 \\
\hline
\end{tabular}




\begin{tabular}{|c|c|c|c|c|c|c|c|c|}
\hline 44 & Red & Kathidhan & 0.087 & 0.143 & 0.601 & 25.750 & 35.222 & 28.107 \\
\hline 45 & Red & Kundadhan & 0.489 & 0.008 & 0.876 & 30.063 & 56.556 & 39.595 \\
\hline 46 & Red & Champaeisiali & 0.360 & 0.222 & 0.534 & 20.688 & 31.444 & 30.275 \\
\hline 47 & White & Latamahu & 0.493 & 0.189 & 0.141 & 23.375 & 21.444 & 13.584 \\
\hline 48 & Red & Latachaunri & 0.507 & 0.211 & 1.018 & 19.875 & 50.444 & 30.925 \\
\hline 49 & White & AC10608 & 0.427 & 0.087 & 0.108 & 43.125 & 12.333 & 10.414 \\
\hline 50 & White & AC10187 & 0.395 & 0.159 & 0.085 & 30.063 & 37.111 & 12.981 \\
\hline 51 & Red & AC10162 & 0.259 & 0.192 & 0.526 & 45.000 & 81.333 & 32.397 \\
\hline 52 & White & AC7282 & 0.136 & 0.047 & 0.084 & 37.063 & 20.667 & 10.335 \\
\hline 53 & White & AC7269 & 0.119 & 0.005 & 0.204 & 43.938 & 14.111 & 10.189 \\
\hline 54 & White & AC7134 & 0.418 & 0.144 & 0.118 & 46.438 & 17.333 & 6.841 \\
\hline 55 & White & AC7008 & 0.913 & 0.011 & 0.078 & 42.438 & 22.444 & 9.534 \\
\hline 56 & White & AC9093 & 0.357 & 0.215 & 0.061 & 45.750 & 17.000 & 11.270 \\
\hline 57 & White & AC9090 & 0.255 & 0.221 & 0.079 & 48.438 & 16.667 & 10.556 \\
\hline 58 & White & AC9076A & 0.899 & 0.159 & 0.048 & 43.688 & 22.889 & 12.126 \\
\hline 59 & Red & AC9065 & 0.353 & 0.176 & 0.359 & 44.875 & 61.778 & 30.485 \\
\hline 60 & Red & AC9063 & 0.860 & 0.235 & 0.375 & 110.563 & 52.222 & 23.538 \\
\hline 61 & White & AC9058 & 0.573 & 0.126 & 0.055 & 5.313 & 23.222 & 11.698 \\
\hline 62 & White & AC9053A & 0.154 & 0.159 & 0.053 & 42.000 & 17.333 & 9.415 \\
\hline 63 & Red & AC9050 & 0.395 & 0.191 & 0.388 & 28.313 & 54.889 & 32.411 \\
\hline 64 & White & AC9005 & 1.612 & 0.268 & 0.126 & 47.375 & 24.333 & 14.622 \\
\hline 65 & White & AC20389 & 1.247 & 0.279 & 0.035 & 66.250 & 19.333 & 10.102 \\
\hline 66 & White & AC20371 & 0.839 & 0.284 & 0.083 & 110.000 & 32.000 & 6.149 \\
\hline 67 & Red & AC20423 & 0.713 & 0.182 & 0.434 & 46.625 & 53.000 & 33.031 \\
\hline 68 & White & AC20362 & 0.811 & 0.312 & 0.077 & 68.750 & 19.222 & 10.688 \\
\hline 69 & White & AC20328 & 1.331 & 0.312 & 0.078 & 67.500 & 22.000 & 6.076 \\
\hline 70 & White & AC20317 & 0.870 & 0.332 & 0.102 & 79.063 & 23.444 & 10.542 \\
\hline 71 & Red & AC20282 & 1.118 & 0.201 & 1.043 & 84.500 & 76.889 & 42.167 \\
\hline 72 & Red & AC20246 & 1.083 & 0.279 & 2.846 & 67.875 & 69.333 & 41.947 \\
\hline 73 & Red & AC20347 & 1.188 & 0.292 & 0.272 & 57.313 & 23.778 & 27.906 \\
\hline 74 & White & Palinadhan-1 & 0.094 & 0.342 & 0.150 & 38.313 & 21.000 & 14.589 \\
\hline 75 & White & Chatuimuchi & 0.525 & 0.322 & 0.120 & 49.875 & 18.778 & 16.714 \\
\hline 76 & White & Uttarbangalocal-9 & 0.098 & 0.296 & 0.060 & 51.500 & 18.333 & 15.439 \\
\hline 77 & White & Gochi & 0.098 & 0.323 & 0.118 & 42.000 & 22.000 & 14.731 \\
\hline 78 & White & Sugandha-2 & 0.273 & 0.278 & 0.127 & 57.125 & 19.444 & 11.615 \\
\hline 79 & White & Jhingesal & 0.423 & 0.209 & 0.163 & 39.750 & 19.000 & 13.456 \\
\hline 80 & Red & Cheruvirippu & 0.315 & 0.114 & 0.676 & 37.313 & 89.667 & 37.205 \\
\hline 81 & Red & Mahamaga & 0.343 & 0.187 & 0.584 & 38.000 & 40.778 & 33.861 \\
\hline 82 & White & Jaya & 0.091 & 0.079 & 0.093 & 43.688 & 14.778 & 16.255 \\
\hline 83 & Red & D1 & 0.164 & 0.153 & 0.451 & 81.938 & 73.111 & 37.997 \\
\hline 84 & Red & $\mathrm{Pk}-21$ & 0.269 & 0.169 & 0.568 & 40.000 & 44.222 & 32.964 \\
\hline 85 & White & Gandhakasala & 0.066 & 0.250 & 0.129 & 66.750 & 17.000 & 13.353 \\
\hline 86 & Red & Sreyas & 0.217 & 0.148 & 0.618 & 57.375 & 119.889 & 31.495 \\
\hline 87 & Red & Gondiachampeisiali & 0.762 & 0.213 & 0.626 & 24.750 & 54.556 & 24.855 \\
\hline
\end{tabular}

Page 13/30 


\begin{tabular}{|c|c|c|c|c|c|c|c|c|}
\hline 88 & White & Chinamal & 0.748 & 0.300 & 0.111 & 18.313 & 22.222 & 9.104 \\
\hline 89 & White & Magra & 0.146 & 0.311 & 0.119 & 19.875 & 17.111 & 9.971 \\
\hline 90 & Red & Landi & 1.380 & 0.142 & 0.918 & 28.000 & 63.111 & 29.480 \\
\hline 91 & White & Lalgundi & 0.353 & 0.289 & 0.124 & 10.563 & 22.222 & 11.272 \\
\hline 92 & White & Balisaralaktimachi & 0.234 & 0.253 & 0.116 & 18.750 & 39.111 & 11.922 \\
\hline 93 & White & Laxmibilash & 0.289 & 0.191 & 0.211 & 40.813 & 18.667 & 12.139 \\
\hline 94 & Red & Kaniar & 1.027 & 0.214 & 0.651 & 39.000 & 16.778 & 21.532 \\
\hline 95 & White & Kanakchampa & 0.129 & 0.272 & 0.159 & 39.313 & 16.444 & 15.795 \\
\hline 96 & White & Magura-s & 0.210 & 0.295 & 0.134 & 43.063 & 16.000 & 13.512 \\
\hline 97 & White & AC44603 & 1.098 & 0.227 & 0.110 & 60.875 & 43.889 & 13.088 \\
\hline 98 & Red & AC44585 & 0.693 & 0.188 & 0.918 & 61.000 & 80.111 & 38.705 \\
\hline 99 & White & AC44598 & 1.938 & 0.124 & 0.224 & 59.313 & 28.889 & 11.618 \\
\hline 100 & Red & AC44592 & 1.032 & 0.118 & 2.320 & 64.938 & 242.000 & 50.515 \\
\hline 101 & Red & AC44646 & 1.025 & 0.251 & 10.407 & 63.938 & 316.889 & 58.750 \\
\hline 102 & White & AC44604 & 1.259 & 0.203 & 0.149 & 60.313 & 28.889 & 13.015 \\
\hline 103 & White & AC44597 & 1.735 & 0.075 & 0.116 & 54.875 & 40.654 & 13.015 \\
\hline 104 & White & AC44638 & 0.801 & 0.161 & 0.104 & 77.250 & 55.667 & 9.559 \\
\hline 105 & Red & AC44595 & 1.014 & 0.145 & 6.618 & 66.500 & 334.111 & 69.412 \\
\hline 106 & Red & AC44588 & 0.910 & 0.223 & 1.302 & 59.750 & 227.778 & 50.368 \\
\hline 107 & Red & AC44591 & 1.158 & 0.206 & 0.818 & 47.188 & 124.111 & 35.147 \\
\hline 108 & Red & AC44594 & 0.986 & 0.191 & 3.388 & 60.563 & 183.222 & 35.735 \\
\hline 109 & Red & AC43737 & 0.136 & 0.295 & 11.934 & 37.375 & 230.222 & 48.544 \\
\hline 110 & White & AC43660 & 1.197 & 0.292 & 0.220 & 41.250 & 26.778 & 12.955 \\
\hline 111 & White & AC43732 & 0.665 & 0.257 & 0.079 & 31.063 & 33.778 & 35.239 \\
\hline 112 & White & AC43661 & 0.164 & 0.281 & 0.107 & 43.000 & 50.778 & 24.600 \\
\hline 113 & Red & AC43738 & 0.164 & 0.274 & 11.274 & 47.500 & 246.000 & 53.566 \\
\hline 114 & White & AC43669 & 1.028 & 0.243 & 0.115 & 55.063 & 31.505 & 40.175 \\
\hline 115 & White & AC43663 & 0.154 & 0.269 & 0.217 & 40.625 & 62.667 & 15.429 \\
\hline 116 & Red & AC43658 & 0.325 & 0.269 & 19.796 & 38.688 & 79.778 & 52.475 \\
\hline 117 & White & AC43662 & 0.112 & 0.258 & 0.079 & 36.375 & 66.222 & 13.028 \\
\hline 118 & Red & AC43670 & 0.115 & 0.282 & 28.375 & 56.813 & 358.444 & 81.441 \\
\hline 119 & White & AC43675 & 0.168 & 0.238 & 0.115 & 40.875 & 24.444 & 32.678 \\
\hline 120 & Red & AC43676 & 0.161 & 0.186 & 10.280 & 34.188 & 226.333 & 46.288 \\
\hline Mean & & & 0.586 & 0.200 & 1.924 & 48.209 & 61.059 & 20.678 \\
\hline CV & & & 12.25 & 3.100 & 12.800 & 1.810 & 6.700 & 6.200 \\
\hline LSD5\% & & & 0.174 & 0.0582 & 0.389 & 3.523 & 7.833 & 2.421 \\
\hline
\end{tabular}

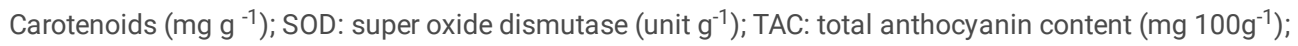

GO: ga y-oryzanol (mg $\left.100 \mathrm{~g}^{-1}\right)$; TFC: Total flavonoids content (mg catechine or CEt $100 \mathrm{~g}^{-1}$ ) and

ABTS : 2,2'-azino-bis 3-ethylbenzothiazoline-6-sulfonic acid (\% inhibition).

Table 2. Estimation of genetic diversity parameters based on 136 SSR marker loci in a panel containing 120 rice germplasm lines 


\begin{tabular}{|c|c|c|c|c|c|c|c|c|}
\hline $\begin{array}{l}\text { Sl. } \\
\text { No }\end{array}$ & Marker & $\begin{array}{l}\text { No. of } \\
\text { Alleles }\end{array}$ & $\begin{array}{l}\text { Range of amplicon } \\
\text { (bp) }\end{array}$ & $\begin{array}{l}\text { Major allele } \\
\text { frquency }\end{array}$ & $\begin{array}{l}\text { Gene } \\
\text { diversity }\end{array}$ & Heterozygosity & PIC & $\begin{array}{l}\text { Inbreeding } \\
\text { coefficient } \\
\text { (f) }\end{array}$ \\
\hline 1 & RM5310 & 4 & $140-190$ & 0.783 & 0.367 & 0.033 & 0.343 & 0.910 \\
\hline 2 & RM582 & 4 & $210-245$ & 0.708 & 0.466 & 0.033 & 0.433 & 0.929 \\
\hline 3 & RM13335 & 4 & $160-180$ & 0.563 & 0.532 & 0.008 & 0.435 & 0.984 \\
\hline 4 & RM6275 & 4 & $140-160$ & 0.721 & 0.447 & 0.058 & 0.411 & 0.870 \\
\hline 5 & RM50 & 4 & $190-205$ & 0.400 & 0.689 & 0.025 & 0.630 & 0.964 \\
\hline 6 & RM85 & 4 & $80-110$ & 0.413 & 0.675 & 0.125 & 0.615 & 0.816 \\
\hline 7 & RM222 & 4 & $210-250$ & 0.629 & 0.557 & 0.025 & 0.519 & 0.956 \\
\hline 8 & RM247 & 5 & $140-200$ & 0.500 & 0.597 & 0.067 & 0.519 & 0.889 \\
\hline 9 & RM328 & 3 & $185-200$ & 0.567 & 0.580 & 0.000 & 0.513 & 1.000 \\
\hline 10 & RM337 & 6 & $155-400$ & 0.446 & 0.668 & 0.117 & 0.612 & 0.827 \\
\hline 11 & RM340 & 5 & $100-220$ & 0.713 & 0.454 & 0.100 & 0.415 & 0.781 \\
\hline 12 & RM470 & 5 & $60-140$ & 0.463 & 0.690 & 0.833 & 0.644 & -0.203 \\
\hline 13 & RM472 & 3 & $290-410$ & 0.513 & 0.508 & 0.092 & 0.387 & 0.821 \\
\hline 14 & RM506 & 3 & $120-130$ & 0.683 & 0.459 & 0.133 & 0.390 & 0.712 \\
\hline 15 & RM1812 & 3 & $130-140$ & 0.442 & 0.607 & 0.000 & 0.523 & 1.000 \\
\hline 16 & RM3701 & 4 & $160-260$ & 0.675 & 0.484 & 0.492 & 0.428 & -0.012 \\
\hline 17 & RM6947 & 3 & $150-160$ & 0.883 & 0.212 & 0.000 & 0.199 & 1.000 \\
\hline 18 & RM14978 & 3 & $240-250$ & 0.417 & 0.639 & 0.000 & 0.563 & 1.000 \\
\hline 19 & RM18776 & 3 & $175-200$ & 0.846 & 0.267 & 0.025 & 0.242 & 0.907 \\
\hline 20 & RM22034 & 3 & $75-85$ & 0.917 & 0.155 & 0.000 & 0.147 & 1.000 \\
\hline 21 & RM24161 & 4 & $270-290$ & 0.542 & 0.612 & 0.117 & 0.552 & 0.811 \\
\hline 22 & RM223 & 5 & $110-170$ & 0.654 & 0.536 & 0.058 & 0.504 & 0.892 \\
\hline 23 & RM440 & 5 & $160-210$ & 0.408 & 0.689 & 0.258 & 0.634 & 0.628 \\
\hline 24 & RM201 & 4 & $150-160$ & 0.467 & 0.645 & 0.217 & 0.581 & 0.666 \\
\hline 25 & RM216 & 4 & $145-160$ & 0.513 & 0.639 & 0.125 & 0.583 & 0.806 \\
\hline 26 & RM258 & 3 & $140-150$ & 0.383 & 0.652 & 0.000 & 0.576 & 1.000 \\
\hline 27 & RM286 & 4 & $100-130$ & 0.471 & 0.632 & 0.100 & 0.562 & 0.843 \\
\hline 28 & RM3735 & 4 & $135-500$ & 0.333 & 0.725 & 0.958 & 0.674 & -0.318 \\
\hline 29 & RM1347 & 3 & $100-110$ & 0.517 & 0.566 & 0.000 & 0.475 & 1.000 \\
\hline 30 & RM7571 & 3 & $130-140$ & 0.713 & 0.433 & 0.008 & 0.373 & 0.981 \\
\hline 31 & RM14723 & 4 & $220-250$ & 0.492 & 0.643 & 0.200 & 0.581 & 0.691 \\
\hline 32 & RM103 & 3 & $255-330$ & 0.492 & 0.559 & 0.767 & 0.461 & -0.369 \\
\hline 33 & RM315 & 3 & $135-140$ & 0.867 & 0.235 & 0.000 & 0.214 & 1.000 \\
\hline 34 & RM225 & 3 & $135-150$ & 0.525 & 0.547 & 0.183 & 0.449 & 0.667 \\
\hline 35 & RM486 & 3 & $130-140$ & 0.654 & 0.469 & 0.108 & 0.380 & 0.770 \\
\hline 36 & RM256 & 3 & $110-150$ & 0.721 & 0.411 & 0.058 & 0.339 & 0.859 \\
\hline 37 & RM1113 & 3 & $150-180$ & 0.671 & 0.457 & 0.058 & 0.373 & 0.873 \\
\hline 38 & RM3423 & 3 & $125-140$ & 0.500 & 0.575 & 0.000 & 0.484 & 1.000 \\
\hline 39 & RM6100 & 3 & $170-180$ & 0.442 & 0.643 & 0.033 & 0.569 & 0.949 \\
\hline 40 & RM590 & 3 & $140-150$ & 0.725 & 0.431 & 0.067 & 0.384 & 0.846 \\
\hline 41 & RM5793 & 3 & $115-130$ & 0.633 & 0.525 & 0.017 & 0.464 & 0.969 \\
\hline
\end{tabular}

Page 15/30 


\begin{tabular}{|c|c|c|c|c|c|c|c|c|}
\hline 42 & RM405 & 3 & $100-110$ & 0.675 & 0.491 & 0.000 & 0.441 & 1.000 \\
\hline 43 & RM547 & 5 & $190-300$ & 0.471 & 0.573 & 0.167 & 0.481 & 0.711 \\
\hline 44 & RM7364 & 5 & $180-250$ & 0.621 & 0.573 & 0.167 & 0.541 & 0.711 \\
\hline 45 & RM205 & 3 & $130-180$ & 0.621 & 0.532 & 0.025 & 0.467 & 0.953 \\
\hline 46 & RM167 & 4 & $130-180$ & 0.704 & 0.463 & 0.100 & 0.421 & 0.786 \\
\hline 47 & RM229 & 5 & $120-140$ & 0.358 & 0.710 & 0.133 & 0.657 & 0.814 \\
\hline 48 & RM20A & 3 & $230-240$ & 0.625 & 0.533 & 0.017 & 0.472 & 0.969 \\
\hline 49 & RM235 & 5 & $100-145$ & 0.396 & 0.719 & 0.175 & 0.671 & 0.758 \\
\hline 50 & RM7003 & 4 & $100-110$ & 0.667 & 0.502 & 0.083 & 0.453 & 0.835 \\
\hline 51 & RM5436 & 4 & $155-190$ & 0.442 & 0.621 & 0.058 & 0.545 & 0.907 \\
\hline 52 & RM25181 & 5 & $130-160$ & 0.379 & 0.710 & 0.167 & 0.660 & 0.767 \\
\hline 53 & RM469 & 3 & $100-110$ & 0.621 & 0.524 & 0.042 & 0.452 & 0.921 \\
\hline 54 & RM6547 & 3 & $155-165$ & 0.867 & 0.240 & 0.017 & 0.226 & 0.931 \\
\hline 55 & RM152 & 4 & $145-155$ & 0.508 & 0.628 & 0.017 & 0.565 & 0.974 \\
\hline 56 & RM148 & 2 & $140-150$ & 0.675 & 0.439 & 0.083 & 0.342 & 0.812 \\
\hline 57 & RM421 & 3 & $250-260$ & 0.458 & 0.631 & 0.000 & 0.555 & 1.000 \\
\hline 58 & RM2634 & 3 & $100-120$ & 0.379 & 0.658 & 0.025 & 0.584 & 0.962 \\
\hline 59 & RM248 & 4 & $75-115$ & 0.346 & 0.732 & 0.117 & 0.684 & 0.842 \\
\hline 60 & RM7179 & 5 & $50-250$ & 0.325 & 0.765 & 0.358 & 0.727 & 0.535 \\
\hline 61 & RM215 & 3 & $155-165$ & 0.617 & 0.491 & 0.017 & 0.392 & 0.966 \\
\hline 62 & RM324 & 4 & $220-260$ & 0.542 & 0.635 & 0.158 & 0.590 & 0.753 \\
\hline 63 & RM317 & 3 & $150-160$ & 0.725 & 0.403 & 0.000 & 0.328 & 1.000 \\
\hline 64 & RM174 & 3 & $230-270$ & 0.508 & 0.621 & 0.067 & 0.551 & 0.893 \\
\hline 65 & RM556 & 3 & $190-210$ & 0.842 & 0.279 & 0.033 & 0.260 & 0.881 \\
\hline 66 & RM257 & 4 & $130-155$ & 0.408 & 0.663 & 0.233 & 0.595 & 0.651 \\
\hline 67 & RM502 & 3 & $260-265$ & 0.808 & 0.318 & 0.000 & 0.281 & 1.000 \\
\hline 68 & RM331 & 4 & $95-115$ & 0.483 & 0.664 & 0.058 & 0.611 & 0.913 \\
\hline 69 & RM403 & 4 & $110-130$ & 0.596 & 0.570 & 0.083 & 0.515 & 0.855 \\
\hline 70 & RM309 & 3 & $180-190$ & 0.696 & 0.460 & 0.025 & 0.405 & 0.946 \\
\hline 71 & RM6641 & 3 & $140-145$ & 0.567 & 0.583 & 0.000 & 0.517 & 1.000 \\
\hline 72 & RM3 & 3 & $110-120$ & 0.383 & 0.663 & 0.033 & 0.589 & 0.950 \\
\hline 73 & RM594 & 3 & $300-320$ & 0.588 & 0.558 & 0.008 & 0.488 & 0.985 \\
\hline 74 & RM3392 & 4 & $160-180$ & 0.504 & 0.615 & 0.108 & 0.545 & 0.825 \\
\hline 75 & RM1278 & 3 & $135-150$ & 0.783 & 0.361 & 0.067 & 0.329 & 0.817 \\
\hline 76 & RM168 & 3 & $95-125$ & 0.625 & 0.510 & 0.150 & 0.431 & 0.708 \\
\hline 77 & RM3375 & 3 & $190-200$ & 0.567 & 0.576 & 0.033 & 0.506 & 0.943 \\
\hline 78 & RM282 & 3 & $140-150$ & 0.725 & 0.436 & 0.000 & 0.395 & 1.000 \\
\hline 79 & RM26632 & 4 & $450-550$ & 0.363 & 0.701 & 0.158 & 0.644 & 0.776 \\
\hline 80 & RM1341 & 3 & $170-190$ & 0.613 & 0.529 & 0.025 & 0.455 & 0.953 \\
\hline 81 & RM4112 & 3 & $160-170$ & 0.488 & 0.623 & 0.158 & 0.549 & 0.748 \\
\hline 82 & RM20377 & 4 & $300-380$ & 0.771 & 0.369 & 0.067 & 0.326 & 0.821 \\
\hline 83 & RM210 & 5 & $130-180$ & 0.363 & 0.734 & 0.700 & 0.687 & 0.051 \\
\hline 84 & RM218 & 4 & $130-160$ & 0.583 & 0.585 & 0.033 & 0.531 & 0.943 \\
\hline 85 & RM494 & 5 & $130-180$ & 0.383 & 0.717 & 0.025 & 0.670 & 0.965 \\
\hline
\end{tabular}

Page 16/30 


\begin{tabular}{|c|c|c|c|c|c|c|c|c|}
\hline 86 & RM336 & 5 & $105-160$ & 0.383 & 0.711 & 0.092 & 0.661 & 0.872 \\
\hline 87 & RM3475 & 4 & $135-160$ & 0.450 & 0.656 & 0.042 & 0.591 & 0.937 \\
\hline 88 & RM480 & 4 & $190-210$ & 0.538 & 0.618 & 0.025 & 0.561 & 0.960 \\
\hline 89 & RM566 & 4 & $150-200$ & 0.433 & 0.656 & 0.017 & 0.591 & 0.975 \\
\hline 90 & RM11701 & 3 & $210-230$ & 0.642 & 0.471 & 0.000 & 0.375 & 1.000 \\
\hline 91 & RM220 & 6 & $85-130$ & 0.358 & 0.745 & 0.183 & 0.703 & 0.756 \\
\hline 92 & RM488 & 6 & $155-200$ & 0.321 & 0.750 & 0.192 & 0.708 & 0.746 \\
\hline 93 & RM6374 & 6 & $130-160$ & 0.338 & 0.771 & 0.075 & 0.737 & 0.904 \\
\hline 94 & RM233 & 5 & $130-160$ & 0.350 & 0.727 & 0.233 & 0.680 & 0.681 \\
\hline 95 & RM112 & 3 & $130-135$ & 0.875 & 0.222 & 0.000 & 0.204 & 1.000 \\
\hline 96 & RM13600 & 4 & $105-130$ & 0.479 & 0.662 & 0.100 & 0.607 & 0.850 \\
\hline 97 & RM495 & 3 & $145-165$ & 0.600 & 0.560 & 0.033 & 0.499 & 0.941 \\
\hline 98 & RM493 & 7 & $180-250$ & 0.283 & 0.813 & 0.558 & 0.787 & 0.317 \\
\hline 99 & RM444 & 5 & $180-240$ & 0.321 & 0.773 & 0.158 & 0.737 & 0.797 \\
\hline 100 & RM468 & 3 & $210-220$ & 0.771 & 0.379 & 0.025 & 0.346 & 0.935 \\
\hline 101 & RM6054 & 3 & $120-130$ & 0.925 & 0.142 & 0.017 & 0.137 & 0.883 \\
\hline 102 & RM509 & 3 & $165-170$ & 0.758 & 0.395 & 0.000 & 0.360 & 1.000 \\
\hline 103 & RM5638 & 6 & $190-240$ & 0.613 & 0.587 & 0.133 & 0.558 & 0.775 \\
\hline 104 & RM8044 & 6 & $240-300$ & 0.279 & 0.761 & 0.233 & 0.721 & 0.695 \\
\hline 105 & RM8271 & 5 & $180-250$ & 0.404 & 0.723 & 0.133 & 0.679 & 0.817 \\
\hline 106 & RM171 & 4 & $380-420$ & 0.517 & 0.633 & 0.058 & 0.575 & 0.909 \\
\hline 107 & RM16686 & 3 & $90-100$ & 0.417 & 0.655 & 0.000 & 0.581 & 1.000 \\
\hline 108 & RM434 & 4 & $250-280$ & 0.567 & 0.595 & 0.025 & 0.537 & 0.958 \\
\hline 109 & RM6091 & 4 & $70-80$ & 0.817 & 0.318 & 0.000 & 0.299 & 1.000 \\
\hline 110 & RM209 & 4 & $145-175$ & 0.542 & 0.612 & 0.000 & 0.552 & 1.000 \\
\hline 111 & RM245 & 4 & $145-155$ & 0.583 & 0.577 & 0.000 & 0.518 & 1.000 \\
\hline 112 & RM1089 & 4 & $210-260$ & 0.417 & 0.637 & 0.067 & 0.565 & 0.896 \\
\hline 113 & RM228 & 4 & 110-170 & 0.625 & 0.544 & 0.192 & 0.491 & 0.650 \\
\hline 114 & RM401 & 3 & $250-300$ & 0.754 & 0.398 & 0.058 & 0.360 & 0.855 \\
\hline 115 & RM11 & 3 & $140-160$ & 0.463 & 0.590 & 0.008 & 0.502 & 0.986 \\
\hline 116 & RM3351 & 3 & $170-190$ & 0.583 & 0.517 & 0.000 & 0.420 & 1.000 \\
\hline 117 & RM5749 & 3 & $130-160$ & 0.588 & 0.504 & 0.025 & 0.400 & 0.951 \\
\hline 118 & RM335 & 2 & $100-110$ & 0.721 & 0.402 & 0.075 & 0.321 & 0.815 \\
\hline 119 & RM144 & 3 & $200-210$ & 0.588 & 0.516 & 0.158 & 0.419 & 0.695 \\
\hline 120 & RM300 & 3 & $125-145$ & 0.867 & 0.238 & 0.017 & 0.221 & 0.930 \\
\hline 121 & RM1132 & 4 & $90-125$ & 0.358 & 0.724 & 0.033 & 0.674 & 0.954 \\
\hline 122 & RM400 & 4 & $210-260$ & 0.367 & 0.717 & 0.467 & 0.665 & 0.353 \\
\hline 123 & RM471 & 3 & $100-120$ & 0.800 & 0.338 & 0.000 & 0.309 & 1.000 \\
\hline 124 & RM243 & 3 & $120-140$ & 0.575 & 0.554 & 0.017 & 0.475 & 0.970 \\
\hline 125 & RM467 & 3 & $200-210$ & 0.558 & 0.575 & 0.000 & 0.502 & 1.000 \\
\hline 126 & RM564 & 4 & $250-300$ & 0.450 & 0.599 & 0.100 & 0.515 & 0.834 \\
\hline 127 & RM8007 & 3 & $130-150$ & 0.767 & 0.385 & 0.000 & 0.352 & 1.000 \\
\hline 128 & RM441 & 4 & $160-200$ & 0.475 & 0.627 & 0.567 & 0.557 & 0.100 \\
\hline 129 & RM518 & 3 & $150-170$ & 0.542 & 0.537 & 0.000 & 0.437 & 1.000 \\
\hline
\end{tabular}

Page 17/30 


\begin{tabular}{|lllllllllll}
130 & RM253 & 4 & $130-170$ & 0.554 & 0.594 & 0.083 & 0.530 & 0.861 \\
131 & RM274 & 3 & $75-80$ & 0.667 & 0.477 & 0.000 & 0.406 & 1.000 \\
132 & RM242 & 4 & $200-240$ & 0.575 & 0.591 & 0.017 & 0.536 & 0.972 \\
\hline 133 & RM3231 & 4 & $170-550$ & 0.346 & 0.703 & 0.650 & 0.645 & 0.080 \\
134 & RM5687 & 4 & $160-500$ & 0.417 & 0.687 & 0.650 & 0.630 & 0.059 \\
\hline 135 & RM5626 & 3 & $165-180$ & 0.583 & 0.512 & 0.733 & 0.411 & -0.430 \\
\hline 136 & RM452 & 3 & $240-250$ & 0.475 & 0.618 & 0.000 & 0.541 & 1.000 \\
\hline
\end{tabular}

Table 3. The inferred ancestry value and population structure of individual member in the panel population with their antioxidants classification 


\begin{tabular}{|c|c|c|c|c|c|c|c|}
\hline \multirow[t]{2}{*}{ SI. No. } & \multirow{2}{*}{$\begin{array}{l}\text { Accession No./ } \\
\text { Vernacular name of germplasm line }\end{array}$} & \multicolumn{5}{|c|}{ Inferred ancestry value at $\mathrm{K}=4$} & \multirow[t]{2}{*}{ Antioxidants content in each germplasm line } \\
\hline & & Q1 & Q2 & Q3 & Q4 & Group & \\
\hline 1 & AC. 5993 & 0.986 & 0.009 & 0.003 & 0.003 & SP1 & high SOD \\
\hline 2 & AC. 6221 & 0.984 & 0.006 & 0.003 & 0.007 & SP1 & Low \\
\hline 3 & AC. 6183 & 0.945 & 0.003 & 0.003 & 0.049 & SP1 & Low \\
\hline 4 & AC. 6170 & 0.994 & 0.002 & 0.002 & 0.002 & SP1 & high Carotenoid \\
\hline 5 & AC. 6023 & 0.978 & 0.009 & 0.002 & 0.012 & $\mathrm{SP} 1$ & high SOD \\
\hline 6 & AC. 6172 & 0.963 & 0.005 & 0.002 & 0.03 & $\mathrm{SP} 1$ & Low \\
\hline 7 & AC. 6027 & 0.012 & 0.002 & 0.983 & 0.002 & SP3 & Low \\
\hline 8 & AC. 6007 & 0.994 & 0.002 & 0.002 & 0.003 & $\mathrm{SP} 1$ & Low \\
\hline 9 & AC. 9006 & 0.973 & 0.006 & 0.009 & 0.012 & SP1 & high \\
\hline 10 & AC. 9021 & 0.927 & 0.053 & 0.005 & 0.015 & $\mathrm{SP} 1$ & Low \\
\hline 11 & AC. 9028 & 0.924 & 0.006 & 0.003 & 0.066 & SP1 & high GO\& SOD \\
\hline 12 & AC. 9030 & 0.989 & 0.005 & 0.001 & 0.005 & SP1 & Low \\
\hline 13 & AC. 9035 & 0.959 & 0.021 & 0.017 & 0.003 & $\mathrm{SP} 1$ & Low \\
\hline 14 & AC. 9038 & 0.982 & 0.015 & 0.001 & 0.002 & SP1 & high SOD \\
\hline 15 & AC. 9043 & 0.95 & 0.046 & 0.002 & 0.002 & SP1 & Low \\
\hline 16 & AC. 9044 & 0.987 & 0.006 & 0.004 & 0.003 & $\mathrm{SP} 1$ & high SOD \\
\hline 17 & AC. 20920 & 0.51 & 0.48 & 0.007 & 0.004 & Admix & high SOD \& Carotenoid \\
\hline 18 & AC. 20907 & 0.866 & 0.131 & 0.001 & 0.002 & $\mathrm{SP} 1$ & high SOD \\
\hline 19 & AC. 20845 & 0.087 & 0.907 & 0.001 & 0.005 & $\mathrm{SP} 2$ & high Carotenoid \\
\hline 20 & AC. 20770 & 0.966 & 0.025 & 0.008 & 0.002 & SP1 & high SOD \& Carotenoid \\
\hline 21 & AC. 20627 & 0.378 & 0.619 & 0.001 & 0.002 & Admix & high Carotenoid \& SOD \\
\hline 22 & AC. 20686 & 0.432 & 0.564 & 0.002 & 0.002 & Admix & high SOD \\
\hline 23 & AC. 20664 & 0.006 & 0.99 & 0.001 & 0.003 & $\mathrm{SP} 2$ & Medium \\
\hline 24 & AC. 20614 & 0.109 & 0.887 & 0.003 & 0.001 & SP2 & high SOD \\
\hline 25 & Jhagrikarti & 0.97 & 0.02 & 0.002 & 0.008 & SP1 & high GO \\
\hline 26 & Dadghani & 0.963 & 0.03 & 0.003 & 0.004 & $\mathrm{SP} 1$ & high SOD \\
\hline 27 & Shayam & 0.004 & 0.002 & 0.993 & 0.002 & SP3 & Very low \\
\hline 28 & Basumati & 0.128 & 0.005 & 0.862 & 0.005 & SP3 & Very low \\
\hline 29 & Bharati & 0.551 & 0.444 & 0.004 & 0.001 & Admix & high SOD \\
\hline 30 & Joha & 0.973 & 0.023 & 0.002 & 0.002 & $\mathrm{SP} 1$ & high SOD \\
\hline 31 & Adira-1 & 0.586 & 0.02 & 0.364 & 0.03 & Admix & Medium \\
\hline 32 & Adira-2 & 0.992 & 0.004 & 0.002 & 0.002 & SP1 & Medium \\
\hline 33 & Adira-3 & 0.256 & 0.327 & 0.413 & 0.004 & Admix & Medium \\
\hline 34 & PK6 & 0.985 & 0.002 & 0.01 & 0.003 & $\mathrm{SP} 1$ & Low \\
\hline 35 & Vachaw & 0.803 & 0.154 & 0.041 & 0.002 & $\mathrm{SP} 1$ & Medium \\
\hline 36 & Kozhivalan & 0.988 & 0.008 & 0.001 & 0.002 & SP1 & Low \\
\hline 37 & Marathondi & 0.017 & 0.486 & 0.464 & 0.033 & Admix & Medium \\
\hline 38 & Ezhoml-2 & 0.862 & 0.135 & 0.002 & 0.001 & SP1 & Medium \\
\hline 39 & Jyothi & 0.973 & 0.025 & 0.001 & 0.001 & SP1 & Medium \\
\hline
\end{tabular}




\begin{tabular}{|c|c|c|c|c|c|c|c|}
\hline 40 & Kantakopura & 0.521 & 0.476 & 0.002 & 0.001 & Admix & Medium \\
\hline 41 & Kantakaamal & 0.055 & 0.585 & 0.207 & 0.153 & Admix & Medium \\
\hline 42 & Kapanthi & 0.032 & 0.296 & 0.333 & 0.339 & Admix & Low \\
\hline 43 & Karpurkanti & 0.001 & 0.042 & 0.956 & 0.001 & SP3 & Very low \\
\hline 44 & Kathidhan & 0.426 & 0.475 & 0.005 & 0.094 & Admix & Medium \\
\hline 45 & Kundadhan & 0.005 & 0.992 & 0.001 & 0.002 & SP2 & Low \\
\hline 46 & Champaeisia & 0.005 & 0.991 & 0.002 & 0.002 & SP2 & high SOD \\
\hline 47 & Latamahu & 0.016 & 0.977 & 0.002 & 0.005 & SP2 & Medium \\
\hline 48 & Latachaunri & 0.028 & 0.966 & 0.002 & 0.005 & SP2 & high SOD \\
\hline 49 & AC. 10608 & 0.981 & 0.013 & 0.001 & 0.005 & SP1 & Low \\
\hline 50 & AC. 10187 & 0.944 & 0.005 & 0.002 & 0.049 & $\mathrm{SP} 1$ & Low \\
\hline 51 & AC. 10162 & 0.941 & 0.012 & 0.021 & 0.026 & $\mathrm{SP} 1$ & Low \\
\hline 52 & AC. 7282 & 0.003 & 0.002 & 0.995 & 0.001 & SP3 & Very low \\
\hline 53 & AC. 7269 & 0.994 & 0.003 & 0.001 & 0.002 & SP1 & Very low \\
\hline 54 & AC. 7134 & 0.749 & 0.032 & 0.21 & 0.009 & Admix & Low \\
\hline 55 & AC. 7008 & 0.94 & 0.057 & 0.001 & 0.002 & SP1 & Low \\
\hline 56 & AC. 9093 & 0.99 & 0.005 & 0.004 & 0.001 & SP1 & high SOD \\
\hline 57 & AC. 9090 & 0.958 & 0.022 & 0.016 & 0.004 & SP1 & high SOD \\
\hline 58 & AC. $9076 \mathrm{~A}$ & 0.844 & 0.148 & 0.001 & 0.007 & $\mathrm{SP} 1$ & Low \\
\hline 59 & AC. 9065 & 0.923 & 0.012 & 0.061 & 0.004 & SP1 & Low \\
\hline 60 & AC. 9063 & 0.667 & 0.324 & 0.001 & 0.008 & Admix & GO \& SOD \\
\hline 61 & AC. 9058 & 0.992 & 0.005 & 0.001 & 0.001 & SP1 & Low \\
\hline 62 & AC. $9053 \mathrm{~A}$ & 0.852 & 0.007 & 0.014 & 0.127 & SP1 & Low \\
\hline 63 & AC. 9050 & 0.894 & 0.097 & 0.007 & 0.002 & SP1 & Low \\
\hline 64 & AC. 9005 & 0.985 & 0.009 & 0.003 & 0.004 & SP1 & high SOD \\
\hline 65 & AC. 20389 & 0.963 & 0.004 & 0.008 & 0.026 & SP1 & high Carotenoid \&SOD \\
\hline 66 & AC. 20371 & 0.976 & 0.019 & 0.001 & 0.004 & SP1 & high GO\&SOD \\
\hline 67 & AC. 20423 & 0.975 & 0.019 & 0.001 & 0.005 & SP1 & Medium \\
\hline 68 & AC. 20362 & 0.968 & 0.013 & 0.006 & 0.013 & $\mathrm{SP} 1$ & high SOD, \\
\hline 69 & AC. 20328 & 0.804 & 0.172 & 0.014 & 0.009 & SP1 & high SOD \\
\hline 70 & AC. 20317 & 0.882 & 0.089 & 0.027 & 0.003 & SP1 & high SOD \\
\hline 71 & AC. 20282 & 0.536 & 0.339 & 0.009 & 0.116 & Admix & high GO \&SOD, \\
\hline 72 & AC. 20246 & 0.639 & 0.262 & 0.069 & 0.03 & Admix & high SOD \& Carotenoid \\
\hline 73 & AC. 20347 & 0.927 & 0.029 & 0.002 & 0.042 & SP1 & high SOD\& Carotenoid \\
\hline 74 & Palinadhan- & 0.321 & 0.038 & 0.381 & 0.26 & Admix & high SOD \\
\hline 75 & Chatuimuchi & 0.001 & 0.001 & 0.996 & 0.001 & SP3 & high SOD \\
\hline 76 & Uttarbangal & 0.743 & 0.155 & 0.002 & 0.101 & Admix & high SOD \\
\hline 77 & Gochi & 0.943 & 0.007 & 0.007 & 0.043 & SP1 & high SOD \\
\hline 78 & Sugandha-2 & 0.003 & 0.002 & 0.995 & 0.001 & SP3 & high SOD \\
\hline 79 & Jhingesal & 0.365 & 0.631 & 0.001 & 0.002 & Admix & high SOD \\
\hline 80 & Cheruviripp & 0.852 & 0.142 & 0.002 & 0.004 & SP1 & Low \\
\hline 81 & Mahamaga & 0.548 & 0.399 & 0.002 & 0.051 & Admix & Very low \\
\hline 82 & Jaya & 0.928 & 0.064 & 0.001 & 0.007 & SP1 & Low \\
\hline 83 & D1 & 0.89 & 0.042 & 0.019 & 0.049 & SP1 & Low \\
\hline
\end{tabular}




\begin{tabular}{|c|c|c|c|c|c|c|c|}
\hline 84 & PK21 & 0.705 & 0.27 & 0.002 & 0.023 & Admix & Low \\
\hline 85 & Gandhakasal & 0.002 & 0.086 & 0.908 & 0.004 & SP3 & high SOD, \\
\hline 86 & Sreyas & 0.909 & 0.085 & 0.003 & 0.002 & SP1 & Medium \\
\hline 87 & GondiAc.hamp & 0.011 & 0.986 & 0.002 & 0.002 & SP2 & high SOD \\
\hline 88 & Chinamal & 0.229 & 0.761 & 0.008 & 0.002 & Admix & high SOD \\
\hline 89 & Magra & 0.267 & 0.726 & 0.005 & 0.003 & Admix & high SOD \\
\hline 90 & Landi & 0.011 & 0.986 & 0.002 & 0.002 & SP2 & Low \\
\hline 91 & Lalgundi & 0.005 & 0.988 & 0.004 & 0.003 & SP2 & high SOD \\
\hline 92 & Balisaralak & 0.004 & 0.99 & 0.002 & 0.003 & SP2 & VL,L,SOD \\
\hline 93 & Laxmibilash & 0.005 & 0.465 & 0.527 & 0.003 & Admix & Very low \\
\hline 94 & Kaniar & 0.03 & 0.958 & 0.006 & 0.007 & SP2 & high Carotenoid \&SOD \\
\hline 95 & Kanakchampa & 0.037 & 0.95 & 0.009 & 0.004 & SP2 & high SOD \\
\hline 96 & Magura-S & 0.003 & 0.984 & 0.012 & 0.001 & SP2 & high SOD \\
\hline 97 & AC. 44603 & 0.014 & 0.017 & 0.001 & 0.967 & SP4 & high Carotenoid \&SOD \\
\hline 98 & AC. 44585 & 0.005 & 0.003 & 0.012 & 0.981 & SP4 & Low \\
\hline 99 & AC. 44598 & 0.02 & 0.003 & 0.01 & 0.968 & SP4 & high Carotenoid \\
\hline 100 & AC. 44592 & 0.001 & 0.001 & 0.014 & 0.984 & SP4 & high Carotenoid, TFC,ABTS \\
\hline 101 & AC. 44646 & 0.002 & 0.001 & 0.001 & 0.996 & SP4 & high Carotenoid ,TAC,TFC,SOD, ABTS \\
\hline 102 & AC. 44604 & 0.028 & 0.004 & 0.012 & 0.956 & SP4 & high Carotenoid \&SOD \\
\hline 103 & AC. 44597 & 0.002 & 0.003 & 0.001 & 0.994 & SP4 & high TFC \&Carotenoid \\
\hline 104 & AC. 44638 & 0.001 & 0.001 & 0.701 & 0.297 & Admix & Low \\
\hline 105 & AC. 44595 & 0.007 & 0.003 & 0.011 & 0.978 & SP4 & high SOD, Carotenoid,ABTS, \\
\hline 106 & AC. 44588 & 0.002 & 0.001 & 0.001 & 0.995 & SP4 & High ABTS \\
\hline 107 & AC. 44591 & 0.002 & 0.002 & 0.001 & 0.995 & SP4 & high Carotenoid \& SOD \\
\hline $\mathrm{C08}$ & AC. 44594 & 0.011 & 0.006 & 0.002 & 0.981 & SP4 & high SOD \\
\hline 109 & AC. 43737 & 0.003 & 0.002 & 0.002 & 0.993 & SP4 & high TAC \&SOD \\
\hline 110 & AC. 43660 & 0.003 & 0.003 & 0.001 & 0.993 & SP4 & high Caro,TAC,TFC,SOD, ABTS \\
\hline 111 & AC. 43732 & 0.002 & 0.001 & 0.001 & 0.995 & SP4 & high SOD \&ABTS \\
\hline 112 & AC. 43661 & 0.006 & 0.004 & 0.001 & 0.989 & SP4 & high SOD, \\
\hline 113 & AC. 43738 & 0.002 & 0.004 & 0.002 & 0.992 & SP4 & high SOD, ABTS,TAC, \\
\hline 114 & AC. 43669 & 0.006 & 0.004 & 0.003 & 0.987 & SP4 & high Caro,TAC,TFC,SOD, \\
\hline 115 & AC. 43663 & 0.002 & 0.002 & 0.002 & 0.994 & SP4 & high SOD \\
\hline 116 & AC. 43658 & 0.001 & 0.001 & 0.001 & 0.997 & SP4 & High TAC \&SOD \\
\hline 117 & AC. 43662 & 0.004 & 0.002 & 0.027 & 0.967 & SP4 & High SOD \\
\hline 118 & AC. 43670 & 0.003 & 0.003 & 0.18 & 0.815 & SP4 & High SOD, ABTS, TAC, \\
\hline 119 & AC. 43675 & 0.003 & 0.002 & 0.014 & 0.98 & SP4 & High TAC,SOD \\
\hline 120 & AC. 43676 & 0.007 & 0.015 & 0.043 & 0.935 & SP4 & High SOD \\
\hline
\end{tabular}

Table 4. Analysis of molecular variance (AMOVA) of the sub-populations of the panel population for antioxidant content 120 rice genotypes 


\begin{tabular}{|c|c|c|c|c|}
\hline \multirow[t]{2}{*}{ Source of variation } & \multicolumn{4}{|c|}{ AMOVA for the four subpopulations at $\mathrm{K}=4$} \\
\hline & df. & Mean sum of squares & Variance components & Percentage variation \\
\hline Among populations & 4 & 551.634 & 2.575 & $6 \%$ \\
\hline Among individuals (accessions) within population & 115 & 2983.721 & 0.000 & $0 \%$ \\
\hline Within individuals (accessions) & 120 & 5027.000 & 41.892 & $94 \%$ \\
\hline Total & 239 & 8562.354 & 44.467 & $100 \%$ \\
\hline F-Statistics & Value & $P$-value & & \\
\hline $\mathrm{F} \quad \mathrm{ST}$ & 0.071 & 0.001 & & \\
\hline$F$ is & -0.235 & 1.000 & & \\
\hline F IT & -0.148 & 1.000 & & \\
\hline F st max. & 0.501 & & & \\
\hline $\begin{array}{ll}F^{\prime} \quad S T\end{array}$ & 0.141 & & & \\
\hline
\end{tabular}

Table 5. Marker-trait associations with antioxidant content in the panel population detected by both the models of GLM and MLM at $p<0.01$.

\begin{tabular}{|c|c|c|c|c|c|c|c|c|c|c|c|c|}
\hline \multirow[t]{2}{*}{ SL.No } & \multirow{2}{*}{$\begin{array}{l}\text { Antioxidant } \\
\text { compounds }\end{array}$} & \multirow[t]{2}{*}{ Marker } & \multirow{2}{*}{$\begin{array}{l}\text { Position } \\
\text { (cM) }\end{array}$} & \multicolumn{4}{|l|}{ GLM } & \multicolumn{5}{|l|}{ MLM } \\
\hline & & & & Marker_F & Marker_p & Marker_R2 & q -value & Marker & Marker_F & Marker_p & Marker_R ${ }^{2}$ & q-va \\
\hline 1 & SOD & RM582 & $\begin{array}{l}66.4- \\
66.4 \mathrm{cM}\end{array}$ & 7.51326 & 0.00713 & 0.0617 & 0.0617 & RM582 & 10.35724 & 0.00169 & 0.09191 & $0.00 !$ \\
\hline 2 & SOD & RM405 & $\begin{array}{l}28.6- \\
28.6 \mathrm{cM}\end{array}$ & 8.28345 & 0.00479 & 0.06759 & 0.06759 & RM405 & 12.0128 & 7.52E-04 & 0.10661 & $0.00 !$ \\
\hline 3 & SOD & RM467 & $\begin{array}{l}46.8- \\
46.8 \mathrm{cM}\end{array}$ & 9.70831 & 0.00233 & 0.07829 & 0.07829 & RM467 & 9.70377 & 0.00234 & 0.08612 & $0.00 !$ \\
\hline 5 & TAC & RM440 & $\begin{array}{l}92.7- \\
92.7 \mathrm{~cm}\end{array}$ & 10.07764 & 0.00194 & 0.06646 & 0.06646 & RM440 & 9.06064 & 0.00323 & 0.08013 & 0.00 ? \\
\hline 6 & TAC & RM5638 & $86-86 \mathrm{cM}$ & 12.02036 & 7.47E-04 & 0.07803 & 0.07803 & RM5638 & 11.04573 & 0.0012 & 0.09768 & 0.00 ? \\
\hline 7 & TAC & RM253 & $37-37 \mathrm{cM}$ & 11.30677 & 0.00106 & 0.07443 & 0.07443 & RM253 & 10.51261 & 0.00157 & 0.09297 & $0.00 !$ \\
\hline 8 & TAC & RM5626 & 99-99cM & 9.36875 & 0.00276 & 0.06215 & 0.06215 & RM5626 & 9.35822 & 0.00278 & 0.08276 & 0.00 ? \\
\hline 9 & GO & RM3701 & $\begin{array}{l}45.3- \\
45.3 \mathrm{~cm}\end{array}$ & 14.94433 & 1.87E-04 & 0.11729 & 0.11729 & RM3701 & 9.33336 & 0.00282 & 0.08155 & $0.00 !$ \\
\hline 10 & GO & RM502 & $\begin{array}{l}121.8- \\
121.8 \mathrm{cM}\end{array}$ & 21.52493 & $9.54 \mathrm{E}-06$ & 0.15935 & 0.15935 & RM502 & 8.35407 & 0.00463 & 0.073 & $0.00 t$ \\
\hline 11 & TFC & RM3701 & $\begin{array}{l}\text { 45.3- } \\
45.3 \mathrm{cM}\end{array}$ & 11.62841 & $9.06 \mathrm{E}-04$ & 0.06613 & 0.06613 & RM3701 & 8.95629 & 0.00341 & 0.07279 & 0.00 ? \\
\hline 12 & TFC & RM235 & $\begin{array}{l}101.8- \\
103.8 \mathrm{cM}\end{array}$ & 16.06018 & $1.11 \mathrm{E}-04$ & 0.08746 & 0.08746 & RM235 & 9.20885 & 0.003 & 0.07484 & $0.00 !$ \\
\hline 13 & TFC & RM494 & $\begin{array}{l}124.4- \\
124.4 \mathrm{cM}\end{array}$ & 9.85164 & 0.00217 & 0.05638 & 0.05638 & RM494 & 9.64481 & 0.00241 & 0.07839 & $0.00 !$ \\
\hline 14 & ABTS & RM3701 & $\begin{array}{l}45.3- \\
45.3 \mathrm{~cm}\end{array}$ & 12.55463 & $5.79 \mathrm{E}-04$ & 0.08346 & 0.08346 & RM3701 & 10.97479 & 0.00125 & 0.09699 & $0.00 !$ \\
\hline 15 & ABTS & RM235 & $\begin{array}{l}101.8- \\
103.8 \mathrm{cM}\end{array}$ & 8.08868 & 0.0053 & 0.05533 & 0.05533 & RM235 & 7.06457 & 0.00902 & 0.06243 & 0.00 ؟ \\
\hline
\end{tabular}

\section{Figures}




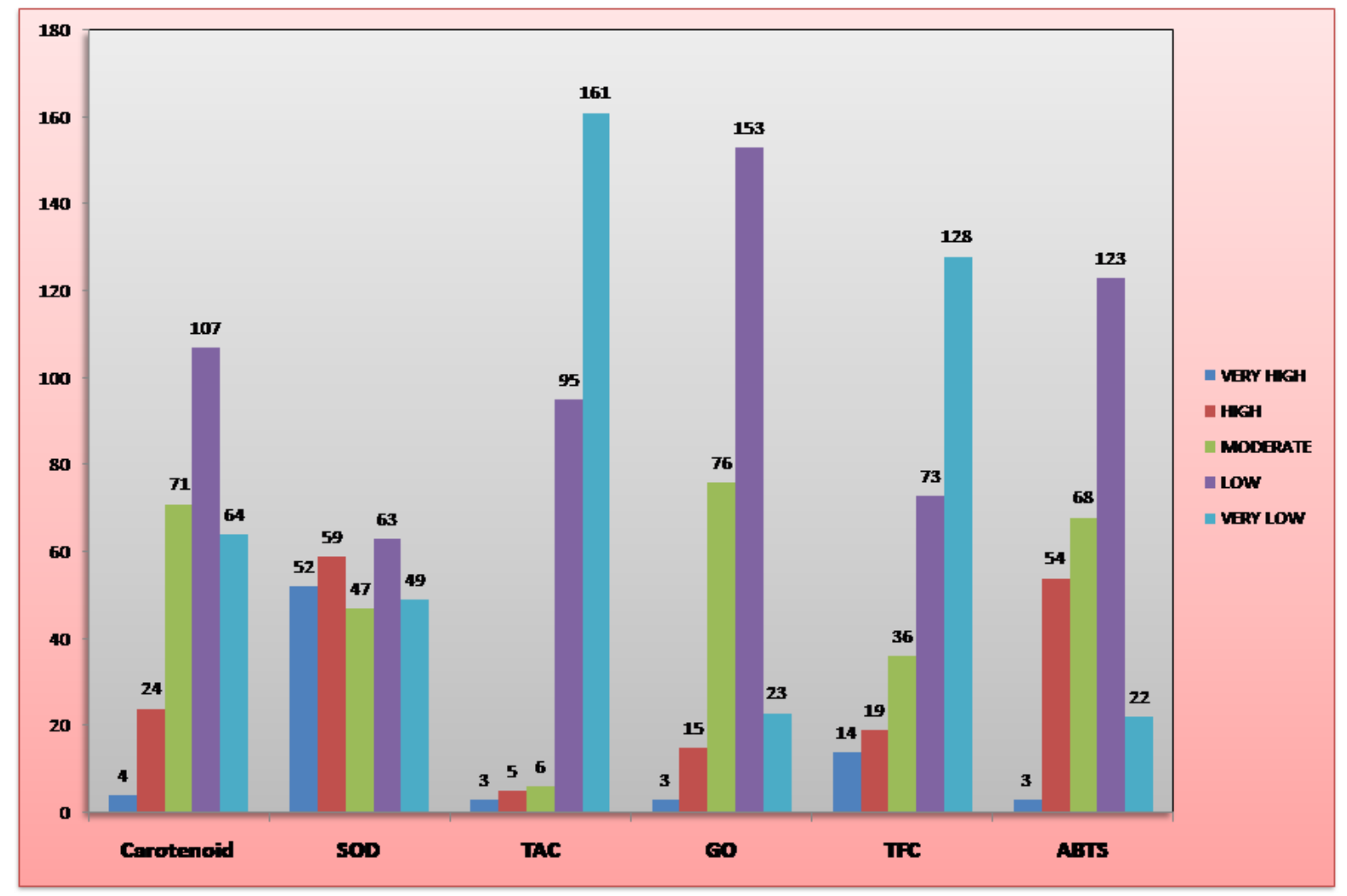

Figure 1

Frequency distribution of germplasm lines for each of the studied antioxidant traits namely carotenoids, superoxide dismutase, anthocyanins, $y$-oryzanol flavonoids, and ABTS present in the shortlisted 270 germplasm lines. 

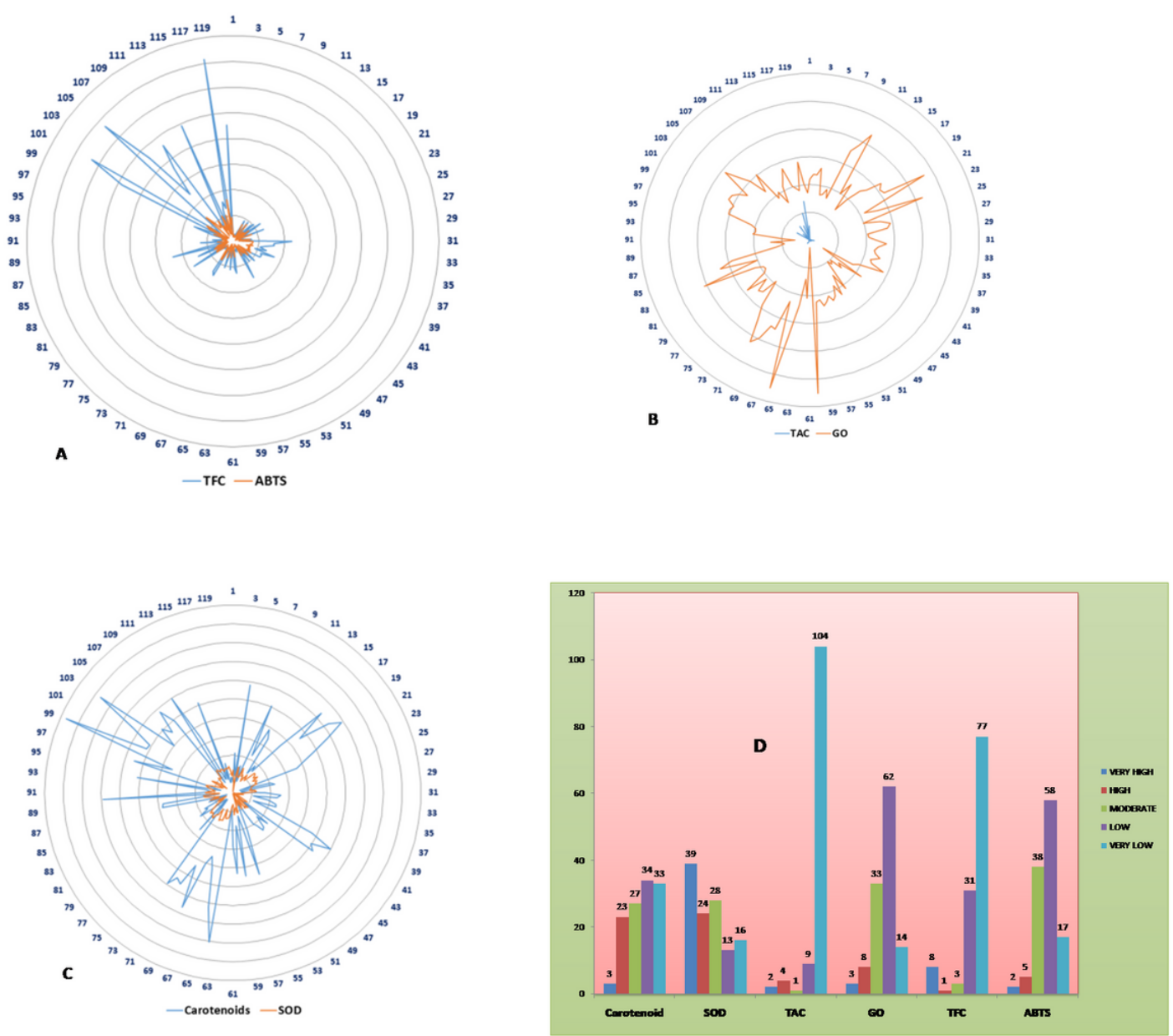

\section{Figure 2}

Antioxidant content of 120 genotypes and their frequency distribution in the panel population. A. Spider graph showing the TFC content \& ABTS activity. B. the TAC \& Y-oryzanol content, C. Carotenoid and SOD content D. Frequency distribution of germplasm lines for carotenoids, superoxide dismutase, anthocyanins, Y-oryzanol, flavonoids, and ABTS in the panel population 


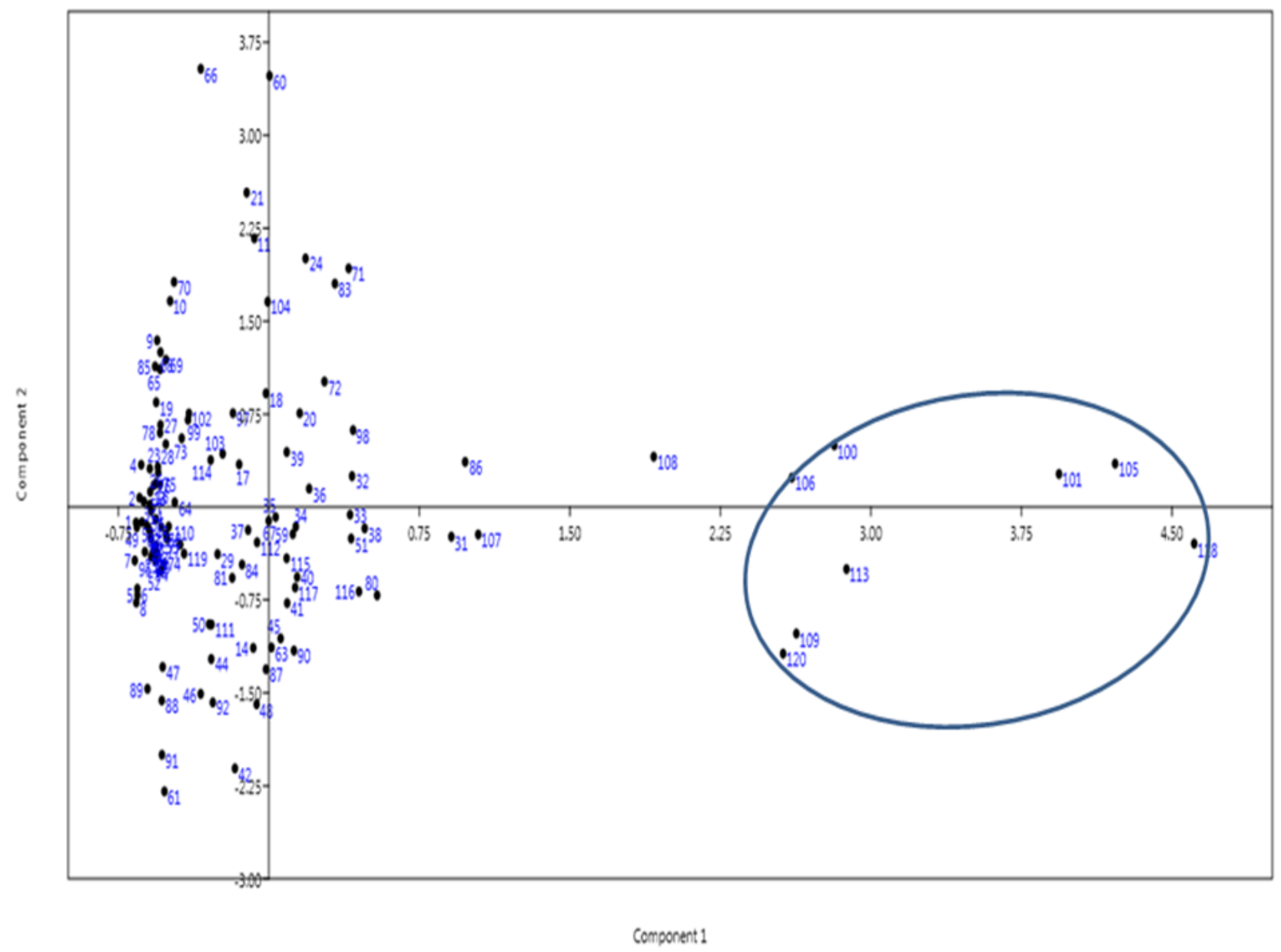

Figure 3

Genotype-by-trait bi-plot diagram showing 120 germplasm lines in two PCs for 6 antioxidant traits. 


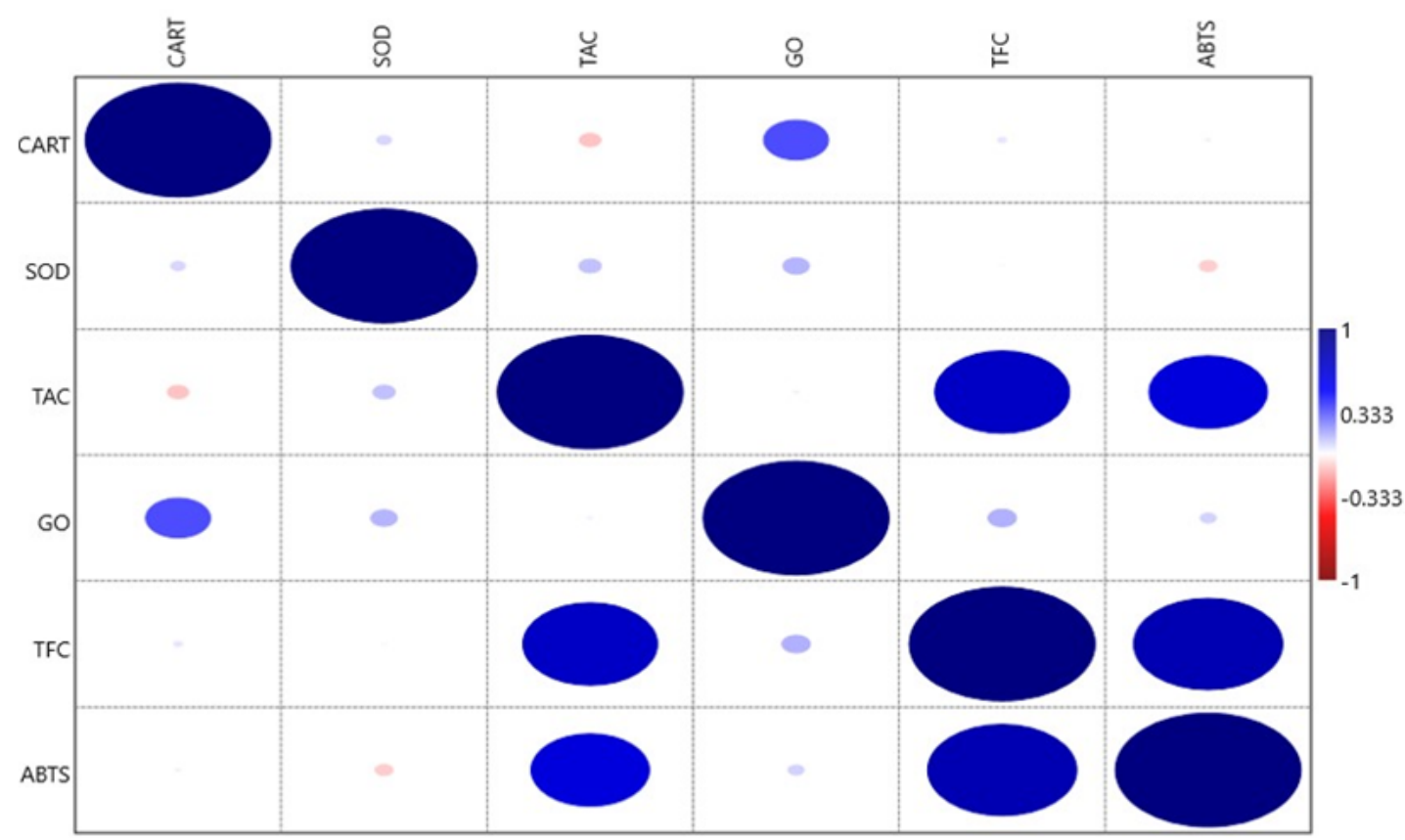

Figure 4

Heat map showing Pearson's correlation coefficients for physiological traits. Significant correlations are colored either in red (negative) or blue (positive). Shades of blue indicate increasing positive correlation coefficient; shades of red indicate increasing negative correlation coefficient. CART: Carotenoids (mg g -1); SOD: super oxide dismutase (unit g-1); TAC: total anthocyanin content (mg 100g-1); G0: $y$-oryzanol (mg $100 \mathrm{~g}-1$ ); TFC: Total flavonoids content (mg catechine or CEt $100 \mathrm{~g}-1$ ); ABTS: 2, 2'-azino-bis 3-ethylbenzothiazoline-6-sulfonic acid (\% inhibition). 

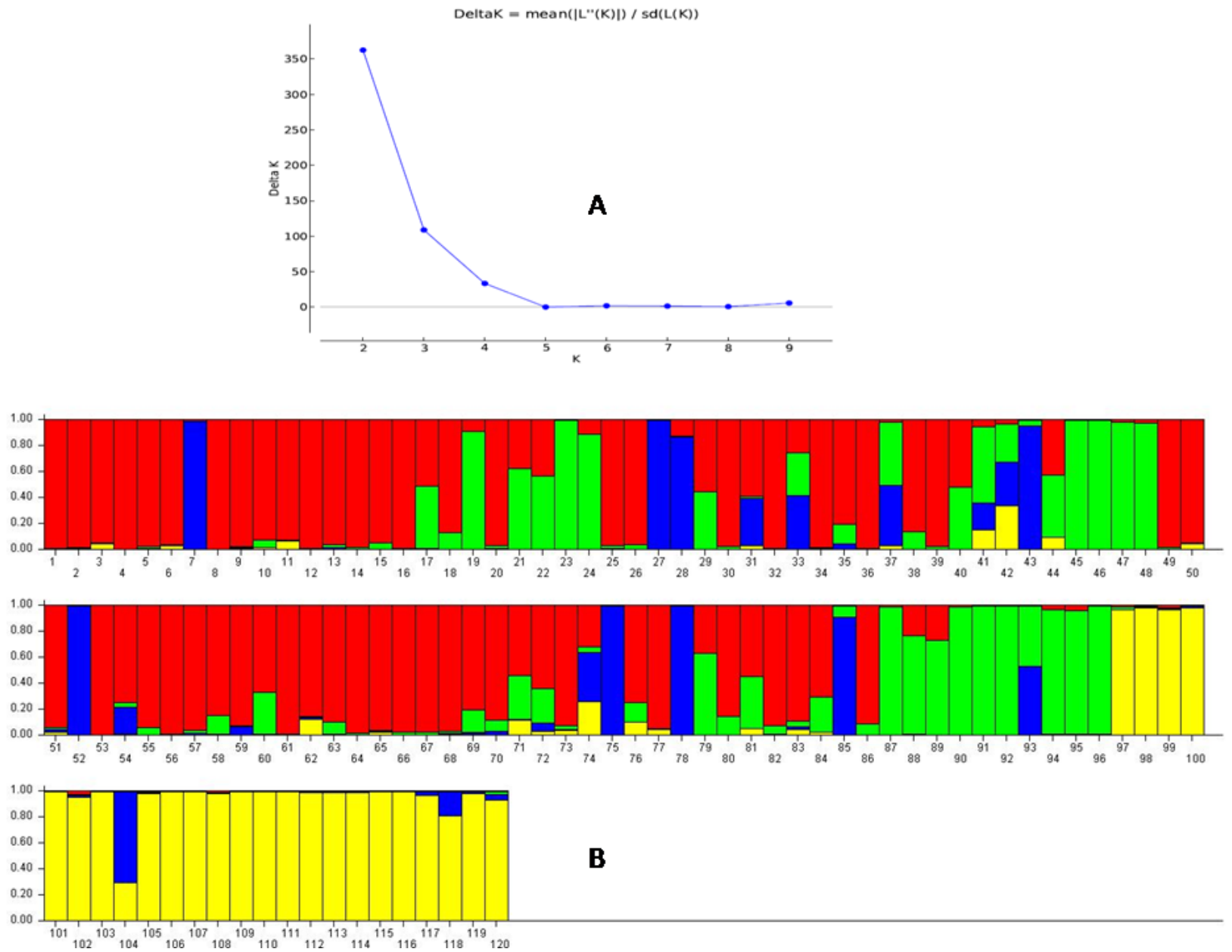

Figure 5

A) Graph of $\Delta K$ value, to the rate of change in the log probability of data between successive $K$ values; $B$ ) Population structure of the panel population based on membership probability fractions of individual genotypes at $\mathrm{K}=4$. The genotypes with the probability of $\geq 80 \%$ membership proportions were assigned as subgroups while others grouped as admixture group. The numbers in the diagram depict the serial number of the germplasm lines listed in the Table 1. 


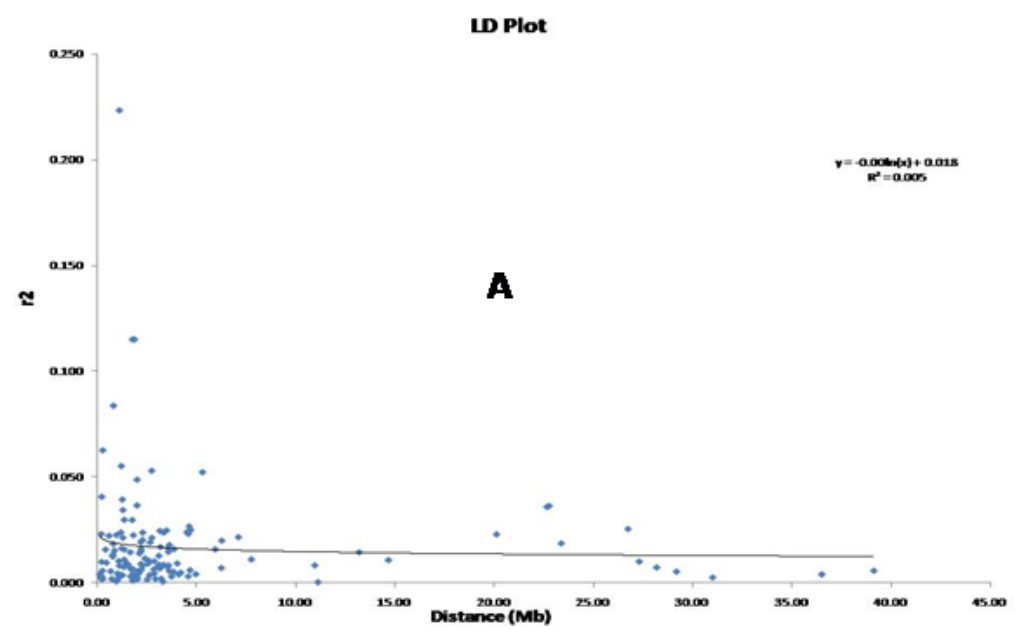

\section{marker_p vs. marker_F and marker_Rsq}

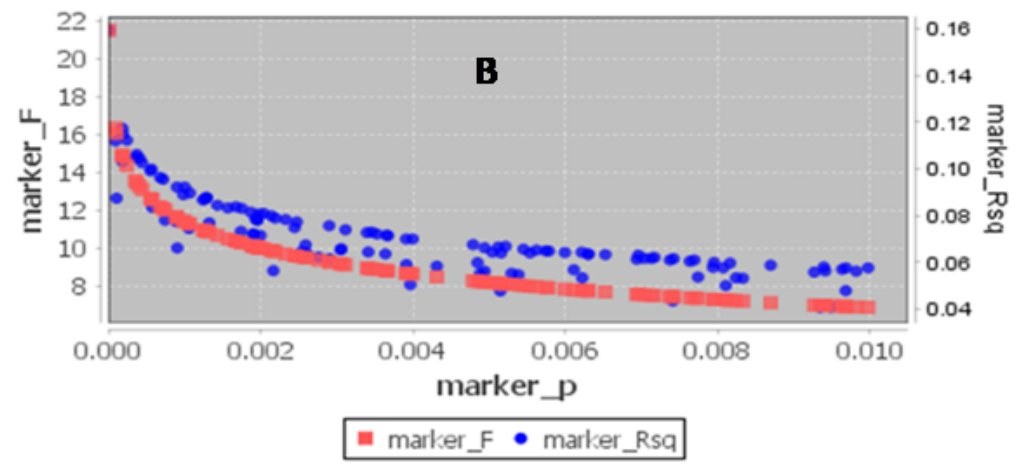

Figure 6

A. The physical distance (base pairs, bp) between pairs of loci on chromosomes against linkage disequilibrium (LD) decay (r2) curve plotted in rice. The decay started in million bp estimated by taking 95 th percentile of the distribution of $\mathrm{r} 2$ for all unlinked loci. B. the marker ' $\mathrm{P}$ ' versus marker ' $\mathrm{F}$ ' and marker R2 
Factorial analysis: (Axes $1 / 2)$

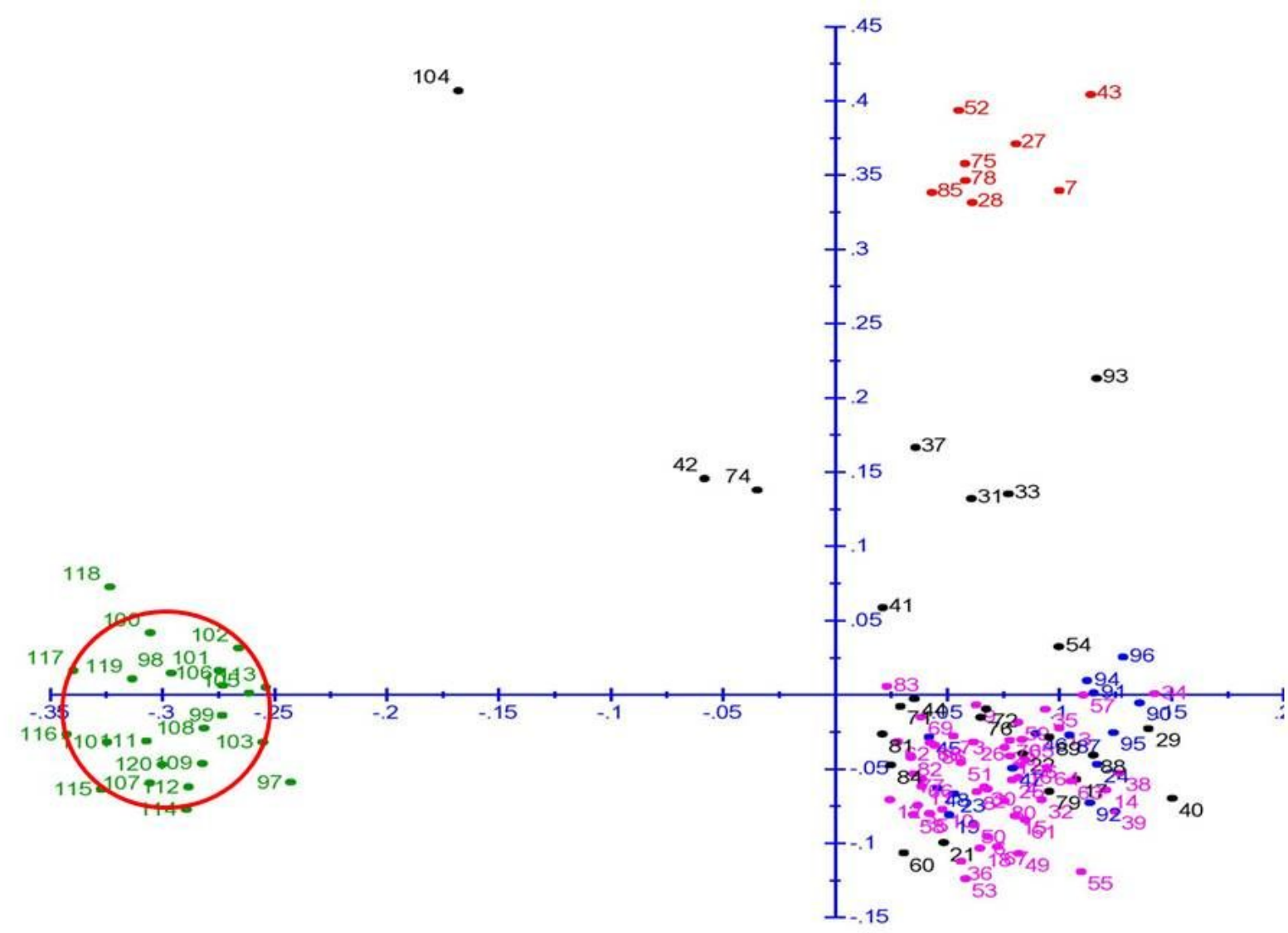

Figure 7

Principal coordinate analysis (PCoA) of 120 genotypes in the panel population for 6 antioxidant traits using 136 molecular markers. The dot numbers in the figure represent the serial number of the genotypes enlisted in the Table 1. The numbers are coloured on the basis of sub-populations obtained from structure analysis (SP1: Pink; SP2; Blue; SP3: Red; SP4: Green \& Admix: Black).
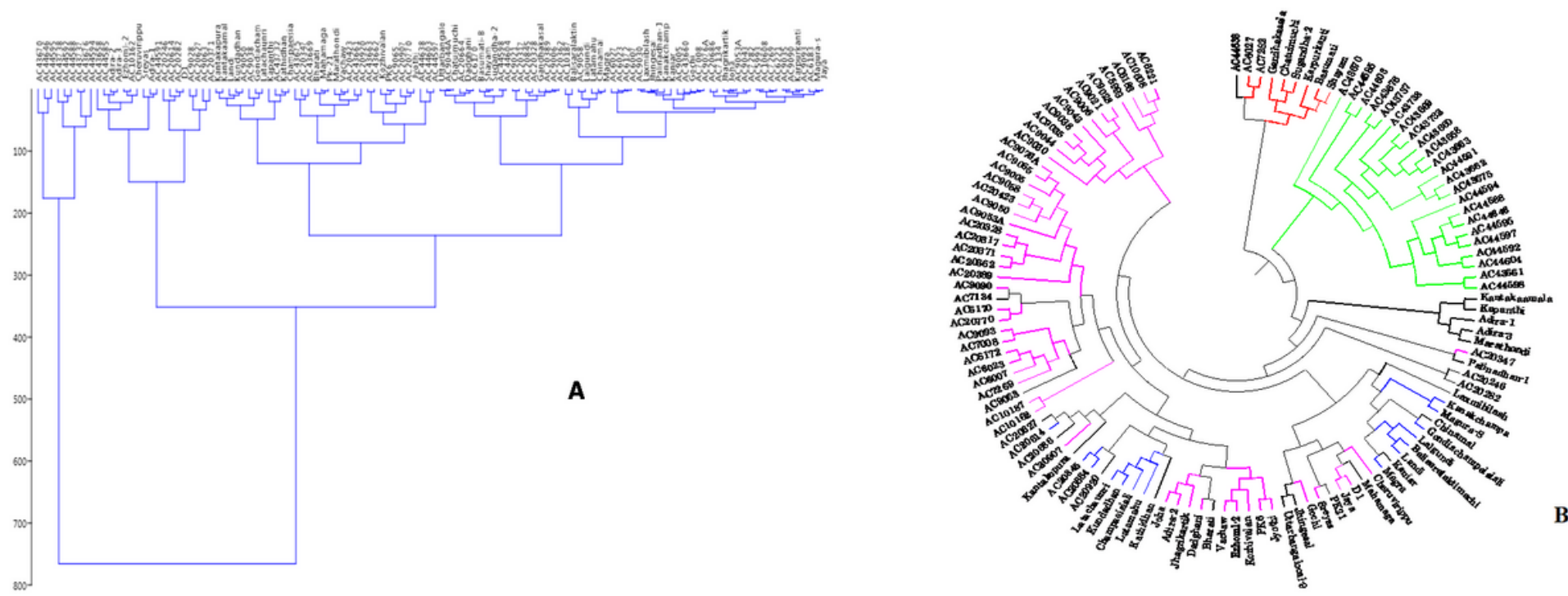

Figure 8

A. Grouping of the panel germplasm lines A. Wards's clustering based on the antioxidant content B.Unrooted tree using unweighted-neighbour joining method depicting clustering pattern of 120 germplasm lines with respect to 136 molecular markers coloured on the basis of sub-populations obtained from structure analysis (SP1: Pink; SP2; Blue; SP3: Red; SP4: Green \& Admix: Black). 


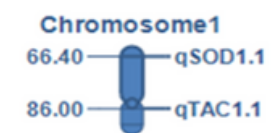

Chromosome5

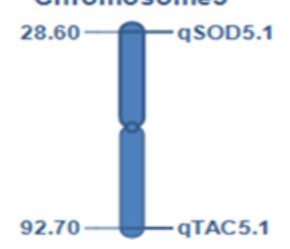

Chromosome6

37.00 -

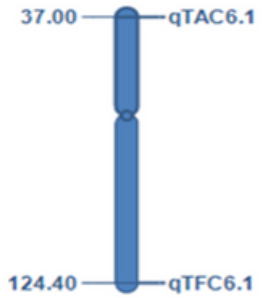

Chromosome3
$99.00-$ qTAC3.1

Chromosome 8

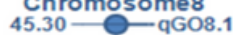

Chromosome10

46.80 - qSOD10.1
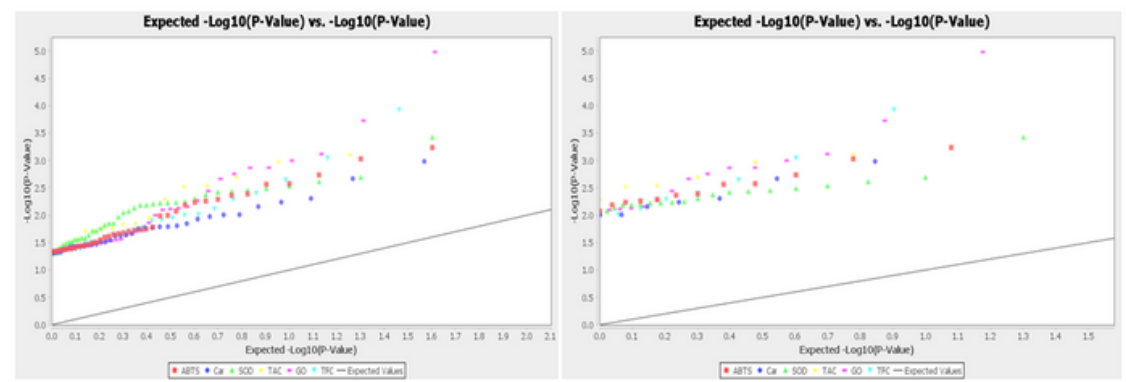

Chromosome11

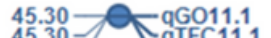

45.30- GIFC11.1

Chromosome12

101.80- ${ }_{101.80}^{\text {qTFC12.1. }}$

\section{Figure 9}

A. Positions of the QTLs on the chromosomes for antioxidant content detected by association mapping in rice. B. Distribution of marker-trait association and quantile-quantile (Q-Q) plot generated from Generalized Linear Model analysis for six antioxidant traits at $(A) p<0.05$ and $(B)$ at $p<0.01$.

\section{Supplementary Files}

This is a list of supplementary files associated with this preprint. Click to download.

- Supplementaryfiles.pdf 